\title{
Evidence for temporal population replacement and the signature of ecological adaptation in a major Neotropical malaria vector in Amazonian Peru
}

\author{
William Lainhart ${ }^{1,2^{*}} \mathbb{D}$, Sara A. Bickersmith², Kyle J. Nadler ${ }^{1}$, Marta Moreno ${ }^{3}$, Marlon P. Saavedra4,
} Virginia M. Chu ${ }^{1,2}$, Paulo E. Ribolla ${ }^{5}$, Joseph M. Vinetz ${ }^{3,6}$ and Jan E. Conn ${ }^{1,2}$

\begin{abstract}
Background: The major Neotropical malaria vector, Anopheles darlingi, was reintroduced into the lquitos, Loreto, Peru area during the early 1990s, where it displaced other anophelines and caused a major malaria epidemic. Since then, case numbers in Loreto have fluctuated, but annual increases have been reported since 2012.

Methods: The population genetic structure of An. darlingi sampled before and after the introduction of long-lasting insecticidal nets (LLINs) was investigated to test the hypothesis of temporal population change (2006 vs. 2012). Current samples of An. darlingi were used to test the hypothesis of ecological adaptation to human modified (highway) compared with wild (riverine) habitat, linked to forest cover. In total, 693 An. darlingi from nine localities in Loreto, Peru area were genotyped using 13 microsatellite loci. To test the hypothesis of habitat differentiation in An. darlingi biting time patterns, HBR and EIR, four collections of An. darlingi from five localities (two riverine and three highway) were analysed.

Results: Analyses of microsatellite loci from seven (2006) and nine settlements (2012-2014) in the lquitos area detected two distinctive populations with little overlap, although it is unclear whether this population replacement event is associated with LLIN distribution or climate. Within the 2012-2014 population two admixed subpopulations, A and B, were differentiated by habitat, with B significantly overrepresented in highway, and both in near-equal proportions in riverine. Both subpopulations had a signature of expansion and there was moderate genetic differentiation between them. Habitat and forest cover level had significant effects on HBR, such that Plasmodium transmission risk, as measured by EIR, in peridomestic riverine settlements was threefold higher than in peridomestic highway settlements. HBR was directly associated with available host biomass rather than forest cover.
\end{abstract}

Conclusions: A population replacement event occurred between 2006 and 2012-2014, concurrently with LLIN distribution and a moderate El Niño event, and prior to an increase in malaria incidence. The likely drivers of this replacement cannot be determined with current data. The present-day An. darlingi population is composed of two highly admixed subpopulations, which appear to be in an early stage of differentiation, triggered by anthropogenic alterations to local habitat.

Keywords: Population replacement, Ecological adaptation, Anopheles darlingi, Malaria, Human biting rate, Microsatellites

\footnotetext{
*Correspondence: wlainhart@albany.edu

${ }^{2}$ Wadsworth Center, New York State Department of Health, Griffin

Laboratory, 5669 State Farm Road, Building 1, Room 101, Slingerlands, NY

12159, USA

Full list of author information is available at the end of the article
} 


\section{Background}

The replacement of a disease vector or an insect agricultural pest with a more benign strain has been a topic of intense research since the late twentieth century [1-4]. Currently, research focused on the control and replacement of Anopheles populations utilizes sterile insect techniques and the creation of transgenic mosquitoes with reduced competence for Plasmodium [5-9]. However, replacement and genetic turnover events do occur naturally, and may be fairly common, given the pressures of changing and altered habitats and environments, as well as influence imposed directly by humans, through insecticide and pesticide application. A recent, documented example of such an event, detected using microsatellites, occurred in the agricultural pest Bemisia tabaci (silverleaf whitefly) in Queensland, Australia. Over a 3-month period, between 2006 and 2007, the most abundant subpopulation of the silverleaf whitefly was nearly completely replaced by a much less abundant one, though the reasons for this replacement are unclear [10]. In New Jersey, over a 9 year period, Aedes albopictus and Aedes japonicus invaded and partially displaced Aedes triseriatus [11]. During this time, the abundance of both Ae. albopictus and Ae. japonicus doubled, while Ae. triseriatus abundance decreased by a factor of three [11]. Although Ae. triseriatus is a known arboviral vector [12], Ae. albopictus and Ae. japonicus have been shown to be much more competent vectors of a wide range of arboviruses, including chikungunya and dengue [13-16]. Additionally, species replacement was observed in anophelines of the Brazilian Amazon (Amazonas state), between August 2008 to March 2010. The authors observed the replacement of Anopheles darlingi with Anopheles albitarsis s.l. following distribution of long-lasting insecticidal nets (LLINs) and increased indoor residual spraying (IRS), that resulted in a decrease in malaria incidence rates in the study localities [17].

Anopheles darlingi was first collected in Peru in 1933, near the Brazilian border of Loreto [18]. Later surveys (1953-1957) conducted by the Ministry of Health detected An. darlingi in localities across Loreto and in one in Cusco department, southern Peru [19]. An intense anti-malaria and insecticide application campaign in 1957 was quite effective, with malaria nearly eliminated in some Peruvian departments within a year [20], and reached a low of 1500 cases in 1965, down from approximately 95,000 in 1944 [21]. In 1965-1966, a survey of anophelines along the Yavarí river (Brazilian border of Loreto) found $A n$. darlingi to be the most abundant species (87\% of 4392 anophelines collected) [22]. Although $A n$. darlingi was still detected in the Yavarí river watershed in 1971 collections, it was absent in the peri-Iquitos area [23]. In a separate study, Anopheles benarrochi was the most abundant anopheline (98\% of those collected, which included Anopheles oswaldoi, Anopheles mattogrossensis, and Anopheles rangeli) in two riverine localities in the Peruvian Amazon [24].

By the late 1980s, DDT insecticide spraying ended in Loreto $[21,25,26]$, in part because no malaria cases were detected in 1988 [21]. Although An. darlingi was not detected in Iquitos in 1989 [27] or in the peri-Iquitos area in 1991 [28], by 1996 it had re-emerged in the Iquitos area concomitantly with a malaria epidemic [21, 29-32]. In the early 1990s, $A n$. darlingi had apparently displaced other anophelines, such as $A n$. benarrochi [22, 24], $A n$. oswaldoi [24] and An. mattogrossensis [28], establishing itself as the most abundant regional anopheline, and the primary malaria vector in several river basins [33-35], i.e., the number of malaria cases rose to over 150,000 in 1997 [21]. Since 2000, case numbers in Loreto have fluctuated from 22,406 (39.6 \% of cases in Peru) in 2000 to 60,186 (93.7\% of cases) in 2014 [36]. The reason(s) for such a dramatic change remain unclear and have not been tested.

Evolutionary diversification is thought to be driven by ecological speciation, which occurs when populations adapt to distinctive environments or habitats, ultimately leading to reproductive isolation [37, 38]. The remarkably broad distribution of $A n$. darlingi from southern Mexico to northern Argentina [39], for years has begged the question of why multiple species have not been detected [40], but see Emerson et al. [41], as they have in An. albitarsis s.l., comprised of nine species, with a similar overall distribution as An. darlingi [42, 43]. One hypothesis is that a predominantly riverine habitat in $A n$. darlingi maintains patterns of population connectivity across diverse biogeographic regions; whereas the shallow sunlit pools where members of An. albitarsis s.l. breed $[44,45]$ may lead to disruption in patterns of gene flow among populations, culminating in speciation. Evidence for diversification in An. darlingi is mixed. Despite significant differentiation between identified genotypes of An. darlingi using microsatellites (genotype 1-Amazonia, genotype 2-Central America, pairwise $F_{S T}$ range 0.1859-0.3901) [46], analysis of two complete An. darlingi mtDNA genomes representing these genotypes supported monotypic species status [47]. Notwithstanding the mtDNA results, a recent study using Restriction site Associated DNA Sequencing (RAD-seq) hypothesizes the existence of three putative species within Brazil, associated with major biogeographical regions [41]. Genetic differentiation within $A n$. darlingi has been explained by geographic barriers and/or isolation by distance [46, 48, 49]; the standing genetic diversity within the species is thought to support phenotypic plasticity in habitat, anthropophagy, exo/endophily, and biting times. 
Population genetic studies of $A n$. darlingi in Peru detected the presence of single, panmictic populations with limited to moderate diversity, using AFLPs [50] or microsatellites [46]. An. darlingi is often referred to as a riverine species [51-53], though an association exists between larval habitats and anthropogenically altered sites, such as fish ponds and pools left by gold-mining and road construction [54, 55]. Two seasonally distinct subpopulations of $A n$. darlingi, were recently discovered along the Madeira River in Rondônia, Brazil, that may provide evidence of adaptation to human-altered habitat [56].

In the Iquitos region, Vittor et al. [25] detected a statistically significant association between forest cover percentage and $A n$. darlingi human biting rate (HBR). The experimental design, which focused on communities along the Iquitos-Nauta highway, found that HBR (from 18:00 to 24:00 h) was highest in peridomestic collections (6.5 bites per person in 0-20\% forest cover) and decreased with increasing forest cover percentage [25]. A more recent survey of communities along the Mazan river, north of Iquitos, found much higher An. darlingi HBRs ranging from 0.102 to 41.13 bites per person per hour, with entomological inoculation rates (EIRs) as high as 5.3 infective bites per person per night in mostly pristine riverside camps used by local fisherman and loggers [34].

The present study extended the HBR studies by Vittor et al. [25] and the population genetics results by Mirabello et al. [46], using An. darlingi collected in highway and riverine habitats, at three levels of forest cover, in the peri-Iquitos region. The following questions were considered: (1) is there a signature of temporal change in $A n$. darlingi populations collected prior to the PAMAFRO LLIN intervention [46] and those collected after the intervention? (2) Were there regional climatic events that might confound such a simple explanation, as in Suriname [57]? (3) Are there genetic differences between riverine and highway populations of $A n$. darlingi? (4) Do the vector biology metrics of HBR and EIR, and risk of Plasmodium infection differ in riverine compared with highway communities? and (5) Is there a direct influence of forest cover level on vector biology metrics?

\section{Methods}

\section{Mosquito collections}

Adult female $A n$. darlingi specimens were collected using human landing catch (HLC) with two collectors in 12-h peridomestic collections in nine localities [San José de Lupuna (LUP), Santo Tomás (STO), Villa Buen Pastor (VBP), El Dorado (DOR), Nuevo Horizonte (NHO), El Triunfo (TRI), Cahuide (CAH), Nuevo Progreso (NPR) and Santa Emilia (SEM)], and identified morphologically [58-60].
Six localities (DOR, NHO, TRI, CAH, NPR and SEM), denoted herein as "deforestation study sites", included collections in chacra (community garden) and forest locations. An Additional file lists the collection and locality information (see Additional file 1). Adult An. darlingi specimens were bisected and the head/thorax of each was sent to the Conn laboratory at the Wadsworth Center (New York State Department of Health) for DNA extraction, genotyping and Plasmodium infection determination. This study was approved by the Human Subjects Protection Program of the University of California San Diego, La Jolla, and by the Comité de Ética of the Universidad Peruana Cayetano Heredia and Asociación Benéfica PRISMA, Lima, Peru. The New York State IRB considers HLC to be an occupational health/risk management issue, and malaria prophylaxis drugs were offered to collectors in accordance with this policy.

\section{Riverine versus highway habitat}

The study area is in the Loreto department of Amazonian Peru, near the city of Iquitos $\left(3.74^{\circ} \mathrm{S}, 73.25^{\circ} \mathrm{W}\right)$. Iquitos, with a population of 406,340 people [61], lies at the intersection of three rivers: the Amazon, the Nanay and the Itaya. Anopheles darlingi specimens were collected in localities situated along the nearby rivers and/or the Iquitos-Nauta highway (Fig. 1).

Vittor et al. [25] reported an association between forest cover level (deforestation) and $A n$. darlingi HBR, avoiding collection of $A n$. darlingi in the riverine area around the intersection of the Itaya River and the Iquitos-Nauta highway. In the present study, the effects of habitat (riverine vs. highway) on $A n$. darlingi population genetics, HBR and EIR were analysed, and compared with those of Vittor et al. [25]. Habitat assignment depended on proximity of the settlement to the nearest river: riverine localities were $<1 \mathrm{~km}$ and highway localities $>2 \mathrm{~km}$ from the nearest river. After habitat assignment, all nineteen Bioclim variables [62] were used to assess differences between habitats, to ensure the biological relevance of this assignment, using Student's t-test $(\alpha=0.10)$.

\section{Determination of forest cover level in highway and riverine communities}

In each locality, a peridomestic collection site was chosen within $10 \mathrm{~m}$ of a home, near the center of the village (visually estimated forest cover level $<20 \%$ ). Chacra and forest sites, in the deforestation study, were at least $1 \mathrm{~km}$ from the peridomestic site, and at least $1 \mathrm{~km}$ from each other. In two remote localities (NPR and SEM), chacra were very near settlements, so distance criteria were modified accordingly. Chacra sites were chosen as an intermediate forest cover level area (visually estimated forest cover 20-60\%) where HBR was expected to be 


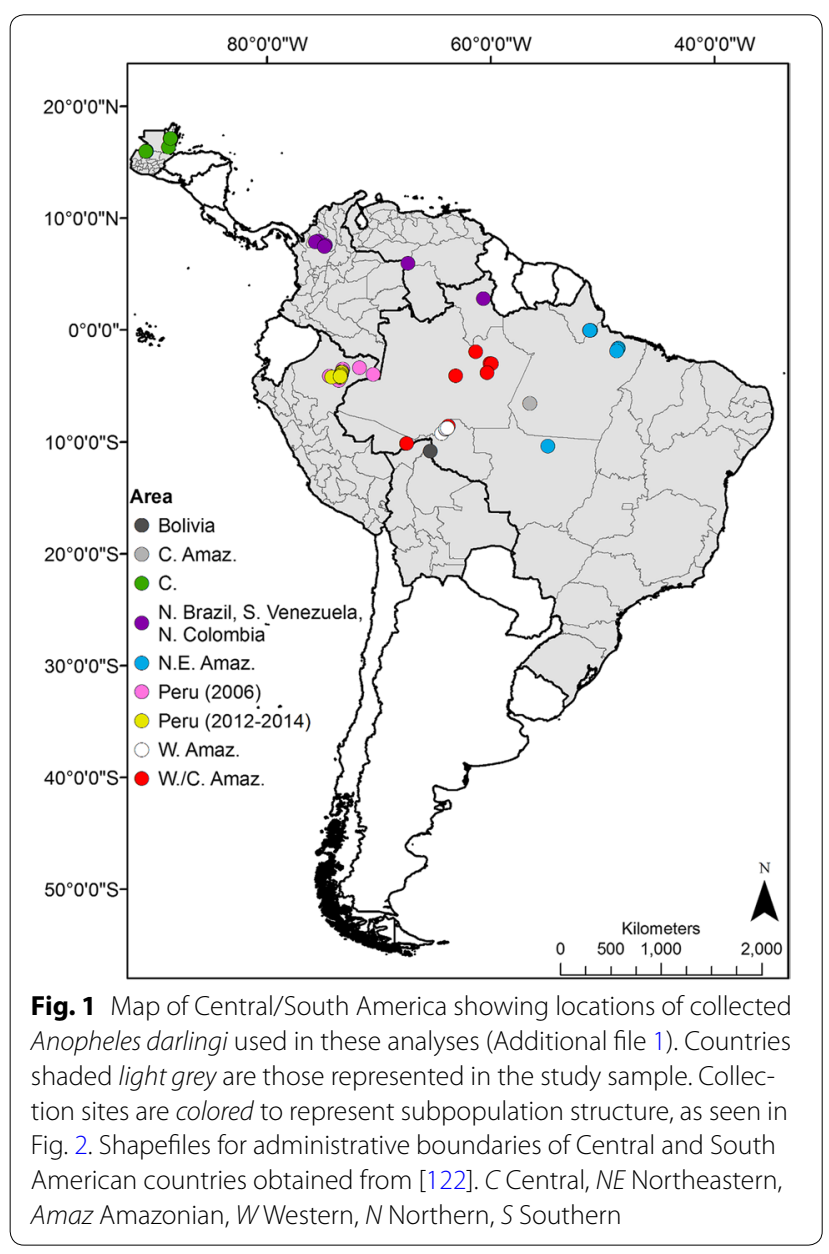

lower than peridomestic and higher than forest sites [25]. These sites were initially deforested for agriculture and are now primarily gardens (banana, manioc other crops), or dense shrubs and high grass. Forest sites were chosen as high forest cover level areas within dense rainforest (visually estimated forest cover $>60 \%$ ) where low HBRs, and little, if any, malaria transmission was expected because of a lack of breeding site types preferred by $A n$. darlingi (low acidity of water bodies and partial shading) [63].

\section{Ground truthing and hemispherical imaging}

Forest cover level near each collection site (3 in each of the six deforestation villages noted above) was estimated using two different methods: satellite and digital hemispherical imagery. GeoEye-1 satellite imagery, 4-bands at $50 \mathrm{~cm}$ resolution, was obtained between September 2013 and August 2014 (LandInfo Worldwide Mapping LLC, Highlands Ranch, CO, USA). Thirty random GPS coordinates were selected within $100 \mathrm{~m}$ of each peridomestic and chacra mosquito collection site using ArcGIS v.10.2.2 (ESRI, Redlands, CA, USA). Within the forest, only the collection site was visited for ground-truthing, due to the very high forest cover and safety concerns. The points were chosen using the "Create Random Points" tool of the Spatial Analyst Extension. Each of these sites was visited and pertinent information was collected, including ground type (i.e., grass, asphalt, bare ground) and forest cover was visually estimated. To determine the percentage of forest within 50 and $100 \mathrm{~m}$ of each collection site, satellite imagery was analysed using ArcGIS v.10.2.2 and GIMP v.2.8.10 image editing software [64]. Images were analysed by manually selecting areas without forest cover, such as bare ground, shrubs, grass, homes or water, removing them, and filling that space with black. The percentage of non-black pixels within the image was then determined using the Color $>$ Info $>$ Histogram tool-all pixels not coloured pure black were considered to be forested (see Additional file 2).

Additionally, at each ground-truthing site, hemispherical images were taken. Digital hemispherical photography can estimate the level of forest canopy $[65,66]$ using a digital camera with a fisheye lens mounted on a tripod, pointing directly upward. An additional image was taken directly north and parallel to the ground, so the site could be characterized appropriately. Each photograph was taken at the same height relative to the ground (approximately $1.36 \mathrm{~m}$ ). The resulting photographs were analysed using CAN-EYE v.6.314 [67]. These images were analysed as "hemispherical images" and "upward" facing. Each image was individually masked so that humans or manmade objects (homes, towers, power lines, etc.) would not be counted as forest canopy. Images were batch analysed (up to 8 images at a time) and an average forest canopy cover (percentage) was reported by the programme per batch. For each collection site, the overall average canopy cover was calculated (see Additional file 3).

Forest cover in the area surrounding mosquito collection sites was calculated, post hoc, using three methods: satellite imagery analysis at $50 \mathrm{~m}$ (SI50) and $100 \mathrm{~m}$ (SI100) radii, and hemispherical photography (HP) at 30 randomly chosen sites within a $100 \mathrm{~m}$ radius (see Additional files 2, 3).

\section{Genotyping and analysis}

Fourteen microsatellite loci $[56,68,69]$ (see Additional file 4) were PCR amplified using fluorescently labelled primers, for each of the An. darlingi specimens collected for genotyping. PCR reactions were $20 \mu \mathrm{L}$ containing $1 \times$ PCR buffer with $1.5 \mathrm{mM} \mathrm{MgCl}_{2}$ (Qiagen), $0.2 \mathrm{mM}$ dNTPs, $0.35 \mu \mathrm{M}$ of each primer, $0.02 \mathrm{U} / \mu \mathrm{L}$ Taq Polymerase (Qiagen), 28:1 Ab:Taq ratio of ClonTech TaqStart antibody and $1 \mu \mathrm{L}$ of genomic DNA. Cycling conditions included an initial denaturation step of $2.5 \mathrm{~min}$ at $95{ }^{\circ} \mathrm{C}$, followed by 35 cycles of denaturation at $94{ }^{\circ} \mathrm{C}$ for $30 \mathrm{~s}$, 
annealing at $60{ }^{\circ} \mathrm{C}$ for $30 \mathrm{~s}$, and elongation at $72{ }^{\circ} \mathrm{C}$ for $30 \mathrm{~s}$; and a final extension step at $72{ }^{\circ} \mathrm{C}$ for 5 or $30 \mathrm{~min}$, depending on microsatellite locus (see Additional file 4). Successful amplification of each sample at all loci was verified on $1 \%$ agarose gels. PCR products were genotyped by the Applied Genomic Technologies Core at the Wadsworth Center, New York State Department of Health using an ABI3730 DNA Analyzer (Applied Biosystems) with GeneScan ${ }^{\mathrm{TM}} 600 \mathrm{LIZ}^{\circledR}$ dye size standard (Applied Biosystems). Data were analysed and alleles called using GeneMapper v.4.0 software (Applied Biosystems). The Microsoft Excel database of alleles was converted to file formats specific to other analysis programs using CONVERT v.1.31 [70].

Initial population genetic analyses were completed comparing the current data set with those published previously [46, 56, 71-73] plus two additional localities from Bolivia and Venezuela (Fig. 1, Additional file 1), using five microsatellite loci (ADC02, ADC28, ADC110, ADC137, $\mathrm{ADC138).} \mathrm{In} \mathrm{these} \mathrm{analyses,} \mathrm{individuals} \mathrm{with} \mathrm{missing}$ data were excluded. Population structure among all genotyped $A n$. darlingi was determined using Bayesian analyses implemented by STRUCTURE v.2.3.4 [74, 75]. These analyses were conducted using the admixture model without prior information regarding sampling group, with correlated allele frequencies, 500,000 burn-in and 2 million MCMC replications for 20 iterations of each $\mathrm{K}=1-15$. The result files were analysed, to determine optimal $\mathrm{K}$ (the $\mathrm{K}$ at which $\Delta \mathrm{K}$ has the largest value), with the Evanno method implemented by STRUCTURE Harvester [76]. The resulting 20 files for optimal $\mathrm{K}$ were averaged, at the population level, using the LargeKGreedy method in the CLUMPP v.1.1.2 program [77]. A CavalliSforza chord distance [78], neighbour joining consensus tree, representing genetic differentiation among populations, was created using Populations v.1.2.31 [79] with 1000 bootstrap replicates. The tree was visualized with Mesquite v.3.02 [80]. Population differences in individual mosquito genotypes, by STRUCTURE subpopulation, were visualized with Factorial Correspondence Analysis (FCA) in GENETIX v.4.05.2 [81].

To test the hypothesis of ecological adaptation to human modified (highway) compared with wild (riverine) habitat, 14 microsatellite loci were analysed in the $A n$. darlingi population in the peri-Iquitos area. Individuals with missing data at more than one locus were excluded. Individual $A n$. darlingi were assigned to subpopulations using the 0.8 membership threshold suggested by Vähä and Primmer [82], after STRUCTURE Bayesian analysis $(K=1-5)$, as described above. The 20 results files for optimal $\mathrm{K}$ were averaged, at the individual level, as above.
Subsequent population genetics analyses were conducted on mosquitoes assigned to a subpopulation, and those not assigned (i.e., admixed) were excluded. Subpopulation differences in individual mosquito genotypes were also visualized by conducting FCA [81].

The average number of alleles $(A)$, and expected and observed heterozygosity ( $H_{E}$ and $H_{O}$, respectively) over all loci, linkage disequilibrium, and deviations from Hardy-Weinberg Equilibrium (HWE) were calculated using Arlequin v.3.5 [83]. The number of private alleles over all loci was obtained using the CONVERT v.1.31 program [70]. Measures of differentiation $\left(F_{S T}\right)$, inbreeding $\left(F_{I S}\right)$, and gene flow (effective number of migrants, $N_{M}$ ) were estimated using the program GENETIX [81, 84]. Non-neutral loci were identified using the program LOSITAN selection detection workbench [85, 86], then removed from the data set. This new data set was then analysed, using LOSITAN, under the Stepwise Mutation Model (SMM), 99.5 \% confidence interval and "Force mean $F_{S T}$ " option to calculate the neutral $F_{S T}$. The data set was also run under the IAM Model, and the same outlier locus was identified. "Neutral $N_{M}$ " was then calculated using the following equation: $N_{M} \approx\left[\left(\frac{1}{F_{S T}}-1\right) \times 0.25\right]$ [87]. In instances of multiple or pair-wise comparisons, the nominal significance level $(\alpha=0.05)$ was adjusted by Bonferroni correction.

Samples from Mirabello et al. [46] were genotyped at an additional eight microsatellite loci, bringing the number of shared loci between those specimens and those in the current study to 13. STRUCTURE Bayesian analyses ( $K=1-5$ ) were conducted, as described above, to verify the differences between these populations. Additionally, allelic distributions, per locus, were compared between populations using the nonparametric KolmogorovSmirnov (KS) test for equality in continuous distribution functions in Rstudio v.0.98.1091 (Boston, MA, USA) using R v.3.1.2 [88]. Finally, STRUCTURE Bayesian analyses $(K=1-5)$ were conducted, as described above but with only ten iterations, to visualize the population structure of the 2006 An. darlingi population.

\section{Real-time PCR for Plasmodium detection}

Individual $A n$. darlingi heads/thoraces were extracted by hand or with a QIAcube using the DNeasy Blood \& Tissue Kit (Qiagen). DNA concentration of each extraction was determined using a Qubit ${ }^{\circledR} 2.0$ fluorometer with the Qubit ${ }^{\circledR}$ dsDNA high sensitivity (HS) assay. Detection of Plasmodium infection was conducted using real-time PCR of the small subunit of the $18 \mathrm{~S}$ rRNA, using a triplex TaqMan assay (Life Technologies), as described in [89]. 


\section{Human biting rate and time and entomological inoculation rate}

Biting time, HBR and EIR were calculated using collection information from 4 monthly, $12-\mathrm{h}$ collections in five of the deforestation study sites. The collections for the calculation of these measurements were undertaken between April and June 2013, the peak malaria transmission season in Loreto [21]. Because Santa Emilia (SEM) was added to this project after it began, it was excluded from the human biting time, HBR and EIR analyses, to ensure comparability among the remaining sites. Human biting time was visualized by plotting the average ( $\pm 95 \%$ confidence intervals) hourly number of $A n$. darlingi collected (18:00-06:00 h) to determine whether biting patterns differed by habitat. The patterns were statistically compared for differences using the $\mathrm{KS}$ test, as described above. HBR was evaluated as the average number of An. darlingi bites per collector per hour. Entomological inoculation rate (EIR) was calculated by multiplying the HBR by the proportion of An. darlingi that were determined to be Plasmodium-positive. The effects of habitat, forest cover and their interaction were statistically evaluated using linear modelling. These effects on EIR were not evaluated due to the small number of infected mosquitoes.

\section{Anopheles darlingi wing length measurements}

Wing lengths were measured, using a stereomicroscope, for a subset of $A n$. darlingi collected in the deforestation sites. Differences in mean ( $\pm 95 \%$ confidence interval) wing length were evaluated by habitat, forest cover level, and their interaction using linear modelling implemented in Rstudio v.0.98.1091, and subpopulation membership using a Student's t-test, with a smaller subset of individuals (not all of the microsatellite genotyped individuals had available wing length measurements).

\section{Results \\ Collection sites and information}

In Loreto, the ecology at the intersection of the highway and river is unknown. Therefore, STO (peri-urban, bordering Nanay river) and $\mathrm{CAH}$ (intersection between Itaya River and Iquitos-Nauta highway) were individually assessed using STRUCTURE results and grouped with the habitat their results most closely matched (STO-highway; CAH-riverine). After final assignments to habitat, statistically significant differences in Bioclim variables for seasonality (Bio4 and Bio7) and extreme/limiting factors (Bio5, Bio8, Bio11, Bio13) in temperature and precipitation were observed between riverine and highway localities $(p<0.10)$. Within peridomestic collection sites, domestic animals were noted as follows: chickens, dogs, cats, cows, ducks, pigs, and turkeys. Domestic animals were detected only at a few chacra sites (cows and pigs), and none were detected in forest sites.

\section{Anopheles darlingi population structure}

STRUCTURE and STRUCTURE Harvester analyses of the comparison among all samples across the Neotropics resulted in an optimal $\mathrm{K}=2$, using five microsatellite loci. When comparing this result to previous studies [46], $\mathrm{K}=2$ was not biologically meaningful. After excluding $\mathrm{K}=2$, STRUCTURE Harvester analyses resulted in an optimal $K=7$ (Fig. 2). According to the STRUCTURE program manual, a $\mathrm{K}$ should be chosen if it represents population structure that can be explained biologically, and if some proportion of individuals are strongly assigned to each of the subpopulations [90]. In this case, $K=7$ meets both criteria. To corroborate the STRUCTURE results, bootstrapped replicates $(\mathrm{n}=1000)$ of collection locality pairwise Cavalli-Sforza chord distances were used to build a neighbor joining consensus tree. As visualized in Fig. 2, results from this analysis and STRUCTURE are congruent. The bootstrap results (values $>50$ shown) are similar to other studies that produced Cavalli-Sforza chord distance trees using species-specific microsatellites [91-93]. Differences among the detected subpopulations were further analysed by FCA analysis (Fig. 3). Axes 1 and 2 explain 25.34 and $21.37 \%$ of the inertia, or variation, in individual $A n$. darlingi genotypes. Two very distinct groups were detected, representing Central American (yellow) versus all South American collection localities (Fig. 3). Within the South American group, clear delineations can be seen between some of the subpopulations. As with the STRUCTURE and the Cavalli-Sforza chord distance tree (Fig. 2), An. darlingi from Peru collected in 2006 and 2012-2014 form two very distinct groups (fuchsia and green, respectively) with little overlap (Fig. 3).

STRUCTURE analyses of the comparison between 2006 [46] and 2012-2014 (current study) An. darlingi resulted in an optimal $\mathrm{K}=2$, using 13 loci (Fig. 4a). The two groupings corresponded to the two collection periods, as predicted. One individual in the 2006 population is a member of the 2012-2014 cluster (Fig. 4a), as determined by STRUCTURE, indicating the presence of this cluster, albeit in a small proportion, in 2006. KS tests identified 9 of 13 loci (ADA03, ADA32, ADA40, ADC02, ADC110, ADC137, ADC28, ADMP9, ADSP2) with statistically significant differences in allele distributions between the 2006 and 2012-2014 An. darlingi populations (Table 1). Moderate differentiation was detected between the two populations $\left(F_{S T}=0.061\right)$.

STRUCTURE reanalyses of the 2006 peri-Iquitos $A n$ darlingi population using 13 loci, resulted in an optimal 

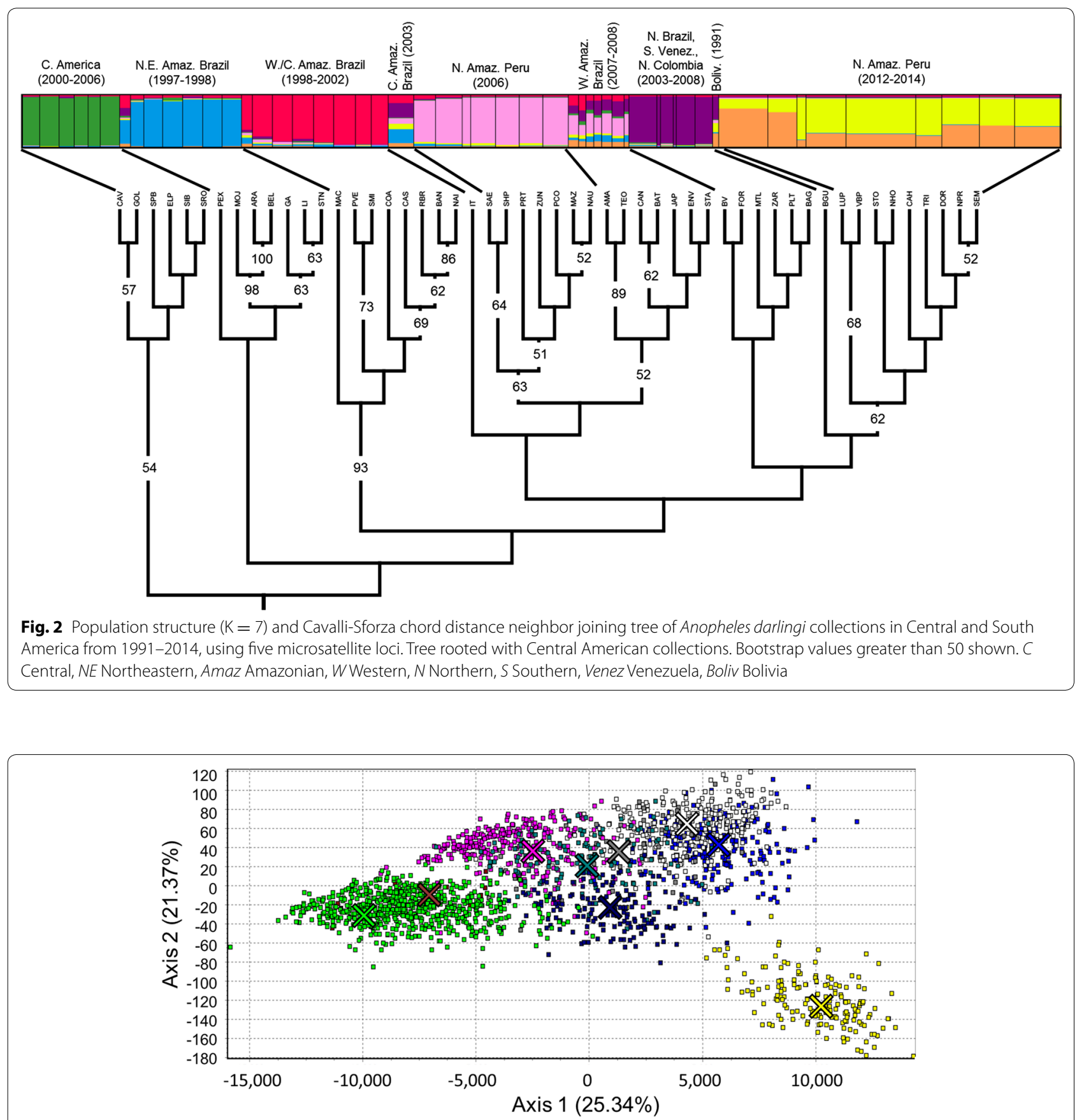

Fig. 3 Factorial correspondence analysis of subpopulations identified in STRUCTURE analyses (Fig. 2). Axes 1 and 2 explain 25.34 and $21.37 \%$ of the inertia in individual Anopheles darlingi genotypes, respectively. Each uniquely colored $X$ corresponds to the centroid of each similarly colored subpopulation. Yellow Central American; blue Northeastern Amazonian Brazil; white Western/Central Amazonian Brazil; grey Central Amazonian Brazil; pink Peru (2006); tea/ Western Amazonian Brazil; dark blue Northern Brazil, Southern Venezuela and Northern Colombia; brown Bolivia; lime green Peru (2012-2014)

$\mathrm{K}=2$ (Additional file 5B). The population of An. darlingi within the five localities from the same region as the current study was composed of two highly admixed subpopulations; in contrast the An. darlingi population in the two localities to the east, near the Brazilian border, was composed of primarily one subpopulation, with little admixture (Additional file 5A, B). 


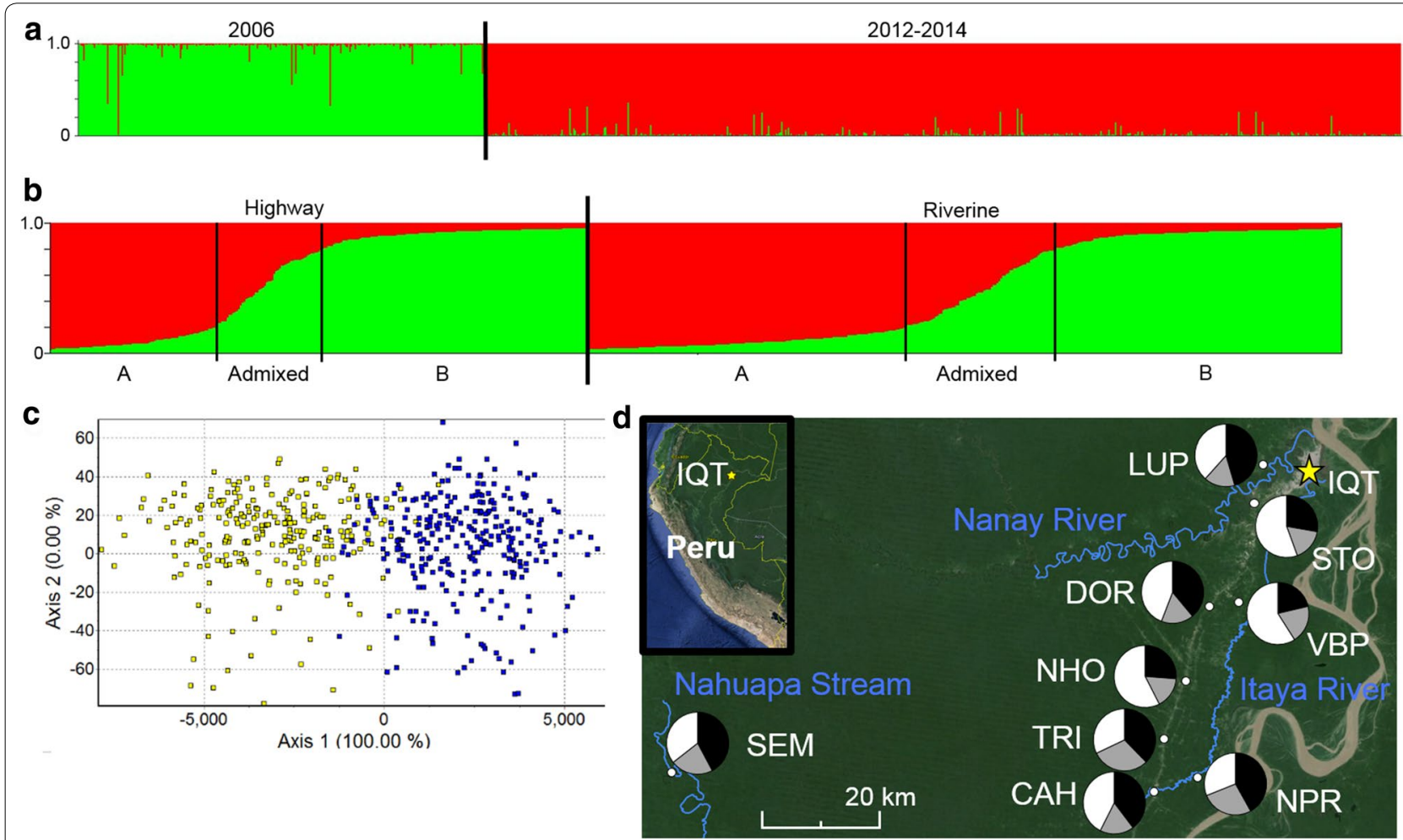

Fig. 4 Population structure of Anopheles darlingi. a Results from the population structure analysis of mosquitoes from 2006 and $2012-2014$ periIquitos, Loreto, Peru collections, using 13 microsatellite loci. Optimal $\mathrm{K}=2$. b Results from the population structure analysis of mosquitoes collected in the current study, using 13 microsatellite loci. Optimal $K=2$. Individuals within each habitat were sorted by subpopulation membership. Vertical bars within Highway and Riverine sections indicate cutoffs for membership to each subpopulation based on a threshold value of 0.8 . Statistically significant differences in distribution of subpopulations by habitat $\left(\chi_{d f=2}^{2}=11.0648, p<0.005\right)$. c Factorial Correspondence Analysis comparing subpopulations (13 microsatellite loci): yellow subpopulation A, blue subpopulation B. Axis 1 explains $100 \%$ of the inertia in individual An. darlingi genotypes. d Map of the area surrounding lquitos, Loreto, Peru (yellow star), depicting An. darlingi collection sites in this study (small white circles). The pie charts on the map, placed near the localities they represent, are the proportion of An. darlingi per detected subpopulation. Two subpopulations were detected in the current study (black subpopulation $A$, white subpopulation B, grey admixed). The lquitos-Nauta highway can be seen in the satellite image, extending southwesterly from lquitos. The Amazon river can be seen along the right-hand edge of the map

The population genetics of An. darlingi from the current study (collected 2012-2014) were initially analysed using 14 microsatellite loci. However, because two of these loci (ADA27 and ADC137) were in linkage disequilibrium $(p<0.0001)$, locus ADA27 was removed and the data were re-analysed using the remaining 13 . STRUCTURE and STRUCTURE Harvester results of An. darlingi show two highly admixed subpopulations (optimal $\mathrm{K}=2$ ): subpopulations A and B (Fig. 4b). A statistically significant difference in distribution of the subpopulations between habitats was detected $\left(\chi_{d f=2}^{2}=11.0648\right.$, $p<0.005$, Fig. 4b, d). Whereas subpopulations A and B are present in approximately equal proportions in the riverine collections (42.08 vs. $37.87 \%$, respectively), subpopulation $\mathrm{B}$ is overrepresented in highway collections compared with A (49.48 vs. $30.80 \%$ respectively). FCA (Fig. 4c) depicts two distinct clusters of genotypes with little overlap in this study: subpopulation A (yellow) and
B (blue); axis 1 explains $100 \%$ of the inertia among individual $A n$. darlingi genotypes. Differences in the distribution of subpopulations among forest cover levels were not significantly different $\left(\chi_{d f=4}^{2}=3.4048, p<0.50\right)$.

\section{Measures of diversity within identified subpopulations}

No significant differences were detected in $A, P_{A}, H_{E}$ or $H_{O}$ between subpopulations $\mathrm{A}$ and $\mathrm{B}$ (Table 2). Evidence of expansion in both subpopulations was detected (Wilcoxon test, SMM model, one tail for $\mathrm{H}$ deficiency, $p=0.00018$ and $p=0.00006$, A and $\mathrm{B}$, respectively). Consistent with population expansion, 22 of 26 exact tests for HWE were significant, and positive $F_{I S}$ values were consistent with inbreeding in both subpopulations (Table 2). Genetic differentiation between subpopulation A and B was moderate $\left(F_{S T}=0.051\right)$, according to Hartl and Clark [94], with moderate gene flow $\left(N_{M}=4.65\right.$; Table 2). After removal of outlier locus $\mathrm{ADC107n}$, as determined by 
Table 1 Testing the differences in allelic distributions per locus between 2006 and 2012-2014 peri-lquitos, Loreto, Peru Anopheles darlingi populations

\begin{tabular}{lc}
\hline Locus & $\begin{array}{l}\text { Kolmogorov-Smirnov one-sided } \\
\text { test } \boldsymbol{p} \text {-values }\end{array}$ \\
\hline ADA03 & 0.0029 \\
ADA20 & 0.3361 \\
ADA32 & 0.0129 \\
ADA40 & 0.0293 \\
ADA41 & 0.7881 \\
ADC02 & $<2.2 \times 10^{-16}$ \\
ADC107n & 0.1836 \\
ADC110 & $6.93 \times 10^{-16}$ \\
ADC137 & 0.0128 \\
ADC138 & 0.6186 \\
ADC28 & $<2.2 \times 10^{-16}$ \\
ADMP9 & 0.0198 \\
ADSP2 & 0.0001 \\
\hline
\end{tabular}

Italics values indicate statistically significant one-sided Kolmogorov-Smirnov tests

Table 2 Measures of diversity, differentiation and gene flow for subpopulations identified in this study

\begin{tabular}{lc}
\hline Subpopulation & All loci $^{\mathbf{a}}$ \\
\hline Current study (A) & \\
$A$ & 10.0 \\
$P_{A}$ & 1.5 \\
$H_{E}$ & 0.711 \\
$H_{O}$ & 0.486 \\
$F_{I S}$ & 0.317 \\
Current study (B) & \\
$A$ & 11.0 \\
$P_{A}$ & 2.7 \\
$H_{E}$ & 0.700 \\
$H_{O}$ & 0.458 \\
$F_{I S}$ & 0.345 \\
Overall & \\
$F_{S T}$ & 0.051 \\
$N_{M}$ & 4.65 \\
Neutral & \\
$F_{S T}$ & 0.022 \\
$N_{M}$ & 11.33 \\
\hline$A n u m b e r$
\end{tabular}

$A$ number of alleles, $P_{A}$ number of private alleles, $H_{E}$ expected heterozygosity, $H_{O}$ observed heterozygosity, $F_{I S}$ inbreeding coefficient, $F_{S T}$ population differentiation, $N_{M}$ number of migrants (gene flow)

a Thirteen microsatellite loci

LOSITAN, the two subpopulations showed little genetic differentiation (neutral $F_{S T}=0.021586$ ) with moderatehigh gene flow (neutral $N_{M}=11.33$, Table 2).

\section{Forest cover, collection, HBR and EIR}

Across all forest cover levels, riverine settlements had significantly more forest cover than highway settlements $\left(p=0.0034,7.4 \times 10^{-6}\right.$ and 0.0452 for SI50, SI100 and $\mathrm{HP}$, respectively, Additional file 6). Additionally, both peridomestic $\left(p=5.9 \times 10^{-14}, 1.27 \times 10^{-11}\right.$ and $<2 \times 10^{-16}$, respectively) and chacra $\left(p=1.65 \times 10^{-6}\right.$, $9.89 \times 10^{-5}$ and $<2 \times 10^{-16}$, respectively) had significantly less forest cover than forest collection sites, regardless of habitat. There was no significant effect of the interaction on forest cover level and habitat on calculated forest cover ( $p=0.351,0.16338$ and 0.102 , respectively), and no significant differences among forest cover calculation methods (adjusted $R^{2}$ : SI50 vs. SI100 $=0.8866$, SI50 vs. $\mathrm{HP}=0.8201$, and SI100 vs. $\mathrm{HP}=0.6983)$.

Anopheles darlingi ( $\mathrm{n}=2067)$ were collected between April and June 2014 in DOR, NHO, TRI, CAH and NPR. On average, the $A n$. darlingi HBR was 17.64 bites per person per 12-h night. Of the mosquitoes collected, $0.63 \%$ were infected $(\mathrm{n}=13 ; P$. vivax-nine, $P$. falciparumthree, Plasmodium spp.--one), resulting in an overall EIR of 0.11 infective bites per person per 12 -h night ( $~ 3.5$ per month; Table 3).

There was a significant effect of forest cover level on HBR $\left(p=2.15 \times 10^{-6}\right)$. Anopheles darlingi were collected most frequently in peridomestic collections $(\mathrm{n}=1778)$ compared with chacra $(\mathrm{n}=193)$ and forest $(\mathrm{n}=96)$. HBR was 45.01 in peridomestic collections, and approximately 9-fold lower (4.97) and 18-fold lower (2.47) in chacra and forest collections, respectively. Infected mosquitoes were collected only in peridomestic (eight Plasmodium vivax, one Plasmodium spp.) and chacra (one P. vivax and three $P$. falciparum). Of the An. darlingi collected near homes, $0.51 \%$ were infected, resulting in an EIR of 0.23 infective bites per person per night ( $\sim 7$ per month). However, in the chacra, $2.07 \%$ of $A n$. darlingi were infected, resulting in an EIR of 0.10 infective bites per person per night $(\sim 3$ per month; Table 3). Thus the risk of Plasmodium transmission to humans is 2.3 -fold higher in peridomestic versus chacra.

The effect of habitat on human biting rate $\left(p=7.23 \times 10^{-6}\right)$ was significant. Riverine collections had an overall HBR of 38.44 compared to 4.28 for highway collections. Nine infected $A n$. darlingi were collected in riverine localities (seven $P$. vivax and two $P$. falciparum), resulting in an EIR of 0.20 infective bites per person per night ( six per month), and four in highway localities (two P. vivax, one P. falciparum and one Plasmodium spp.) resulting in an EIR of 0.06 infective bites per person per night ( $\sim 1.8$ per month; Table 3$)$. Therefore, the risk of Plasmodium transmission to humans is 3.33 -fold higher in riverine compared to highway localities. 
Table 3 The number of Anopheles darlingi collected (April-June 2013), HBR, IR and EIR

\begin{tabular}{|c|c|c|c|c|c|c|c|c|c|c|}
\hline \multirow[t]{2}{*}{ Habitat } & \multirow[t]{2}{*}{ Loc } & \multirow[t]{2}{*}{ Forest cover level } & \multirow[t]{2}{*}{ \# Coll } & \multirow[t]{2}{*}{ \# Coll (mh) } & \multirow[t]{2}{*}{ HBR } & \multicolumn{3}{|c|}{ \# Infected } & \multirow[t]{2}{*}{ IR (\%) } & \multirow[t]{2}{*}{ EIR } \\
\hline & & & & & & Pv & Pf & Pspp & & \\
\hline All & All & All & 2067 & 1406 & 17.64 & 9 & 3 & 1 & 0.63 & 0.11 \\
\hline \multirow[t]{3}{*}{ All } & All & Peridomestic & 1778 & 474 & 45.01 & 8 & & 1 & 0.51 & 0.23 \\
\hline & & Chacra & 193 & 466 & 4.97 & 1 & 3 & & 2.07 & 0.10 \\
\hline & & Forest & 96 & 466 & 2.47 & & & & & \\
\hline \multirow[t]{4}{*}{ Riverine } & All & All & 1762 & 550 & 38.44 & 7 & 2 & & 0.51 & 0.20 \\
\hline & All & Peridomestic & 1552 & 186 & 100.13 & 6 & & & 0.39 & 0.39 \\
\hline & & Chacra & 137 & 182 & 9.03 & 1 & 2 & & 2.19 & 0.20 \\
\hline & & Forest & 73 & 182 & 4.81 & & & & & \\
\hline \multirow[t]{4}{*}{ Highway } & All & All & 305 & 856 & 4.28 & 2 & 1 & 1 & 1.31 & 0.06 \\
\hline & All & Peridomestic & 226 & 288 & 9.42 & 2 & & 1 & 1.33 & 0.13 \\
\hline & & Chacra & 56 & 284 & 2.37 & & 1 & & 1.79 & 0.04 \\
\hline & & Forest & 23 & 284 & 0.97 & & & & & \\
\hline
\end{tabular}

Four, approximately-monthly, 12-h collections; Loc, locality; \# Coll, number collected; mh, man-hours; HBR, human biting rate: the number of bites per person per 12-h night; IR, infection rate: the proportion of collected An. darlingi infected with Plasmodium; EIR, entomological inoculation rate: the number of infective bites per person per 12-h night; Pv, Plasmodium vivax; Pf, Plasmodium falciparum; Pspp, Plasmodium spp.

Habitat and forest cover level had a significant interaction effect on HBR $\left(p=3.99 \times 10^{-11}\right)$. Peridomestic collections in riverine settlements had higher HBR (100.13 vs. 9.42$)$ and EIR (0.39 vs. 0.13$)$ compared to the same collections in highway settlements. The pattern was very similar for chacra collections (HBR: 9.03 vs. 2.37, and EIR: 0.20 vs. 0.04; Table 3). Risk of Plasmodium transmission to humans was three-fold higher in riverine versus highway peridomestic collections and five-fold higher in riverine versus highway chacra collections.

Calculated forest cover using SI50, SI100 and HP had no significant effect on HBR ( $p=0.0904,0.5679$ and 0.0555$)$, though the effect of forest cover as calculated by SI50 and HP approached significance. However, forest cover calculated using SI50 and HP had a significant effect on EIR ( $p=0.01501$ and 0.03130 , respectively), whereas SI100 did not ( $p=0.0745$; Table 3 , Additional file 6). To assess whether distance from human and domestic animals, and not forest cover, was statistically associated with HBR, the distance between the peridomestic, chacra and forest collection sites was measured using ArcGIS 10.2.2. These distances were used in three linear models (one for each forest cover calculation method), and adjusted for both calculated forest cover and habitat. In all three models, increasing distance from the peridomestic collection site resulted in a significant decrease in $\operatorname{HBR}(p=0.00651$, $p=0.00185$ and $p=0.00342$, models adjusting for S150, SI100 and HP, respectively).

\section{Anopheles darlingi biting time}

Significant differences in $A n$. darlingi human biting were detected between riverine (bimodal peaks: 20:00-22:00,
01:00-03:00) and highway habitats (unimodal peak: 21:00-23:00), as tested by Kolmogorov-Smirnov test (one-sided, $p=0.001278$; Fig. 5a). Overall, a significant difference in biting time pattern was detected between both peridomestic and forest (one-sided, $p=0.02862$ ), and chacra and forest (one-sided, $p=0.01633$ ), but not between peridomestic and chacra collections (onesided, $p=0.05604$; Fig. 5b). No significant differences were detected in biting times by subpopulation membership among all collected $A n$. darlingi $(p=0.5248)$ or among $A n$. darlingi collected for the deforestation study $(p=0.4566)$.

\section{Anopheles darlingi wing lengths}

A total of $470 \mathrm{An}$. darlingi collected in deforestation sites were evaluated for differences in wing length by habitat, forest cover level and their interaction, and by subpopulation membership. A linear model showed no relationship between $A n$. darlingi average wing length and habitat ( $p=0.1991)$. However, the effect of forest cover level on average wing length was significant. Mosquitoes captured in forest and chacra sites did not differ in mean wing length (3.193 and $3.194 \mathrm{~mm}$, respectively), whereas those in peridomestic sites had significantly shorter wings (3.121 mm, $p=0.0021)$. There was no significant interaction between habitat and forest cover $(p=0.6592)$, and no effect of subpopulation membership on average wing length (one tailed t-test, $p=0.4488$ ).

\section{Discussion}

Unexpectedly, a population replacement event in $A n$. darlingi in Peru between 2006 and 2012-2014 was 
a

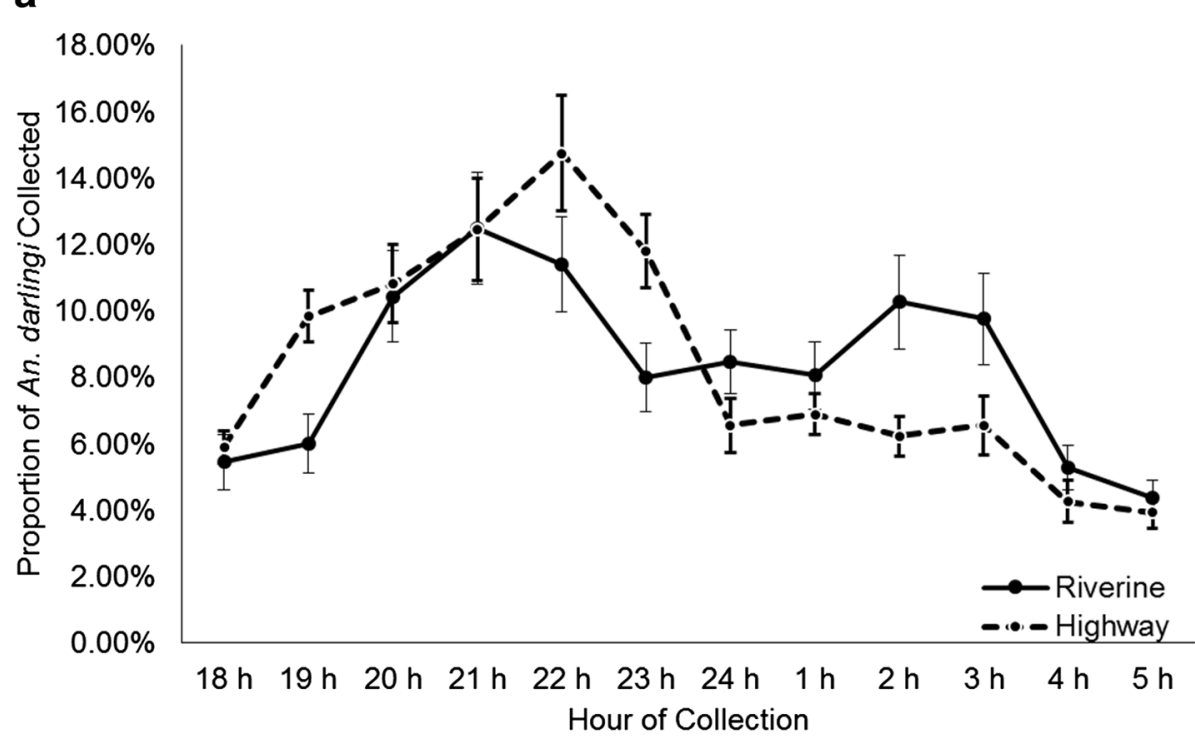

b

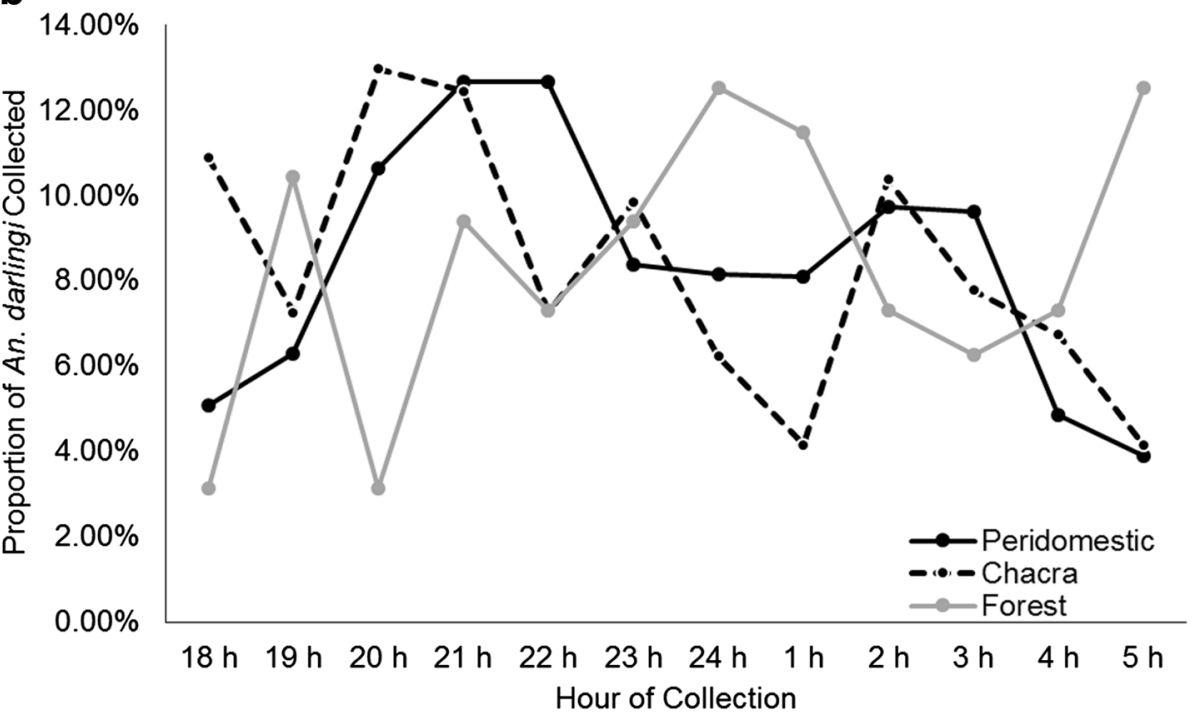

Fig. 5 Average proportion of An. darlingi collected per hour in deforestation sites from April-June 2013. Data represent four, approximately monthly 12-h collections; SEM excluded. a Statistically significant differences noted by habitat: riverine settlements—-solid line, highway settlements-dashed line (Kolmogorov-Smirnov test, one-sided, $p=0.001278$ ). Error bars $95 \%$ confidence intervals. b By forest cover level: peridomestic-solid black line, chacra_dashed black line, forest—-solid grey line (Kolmogorov-Smirnov test, one-sided, peridomestic vs. chacra $p=0.05604$, peridomestic vs. forest $p=0.02862$, chacra vs. forest $p=0.01633$ ). $95 \%$ confidence intervals not shown

detected, using a Cavalli-Sforza chord distance tree (Fig. 2), Bayesian analyses with 13 microsatellite loci (Fig. 4a) and comparing allele frequency distributions per locus among the two populations (Table 1). The CavalliSforza tree, despite its reliance on a fixed evolutionary rate, together with the STRUCTURE results (five microsatellite loci), suggest that the current Iquitos $A n$. darlingi population is most closely related to mosquitoes from Amazonian Bolivia (1991, Fig. 2), but additional samples from southern Colombia and western Amazonas state in Brazil (Fig. 1), and more contemporary collections from the other regions need to be examined to discover the source of the current population. The significant population substructure within $A n$. darlingi between Central and South America, as in previous studies [46], was confirmed. The results of the STRUCTURE analyses using only the $2006 \mathrm{An}$. darlingi collections, reanalysed with 13 loci, were different from those reported by 
Mirabello et al. using five loci [46] and Pinedo-Cancino et al. using AFLPs [50], which reported a single panmictic population of $A n$. darlingi in the peri-Iquitos area. The reanalysed 2006 population was comprised of two subpopulations with different distributions. Among the localities within the region of the current study (MAZ, NAU, PCO, ZUN, PRT) the subpopulations were highly admixed, whereas An. darlingi collected in the two localities east of Iquitos (SPH: $175 \mathrm{~km}$; SAE: $305 \mathrm{~km}$ ) were primarily from one subpopulation, with less admixture (Additional file 5A, B).

Over a time period similar to that of the current study, a Suriname population of An. darlingi collapsed following the introduction of ITNs. Before the 2006 ITN distribution in Suriname, An. darlingi comprised $88.1 \%$ of anophelines collected, with an average HBR of 1.43 bites per person per hour in three study sites. By 2009, postITN distribution, An. darlingi HBR dropped to 0 in the three sites [57]. However, the drop in HBR also coincided with abnormal flooding of rivers throughout the country [57], thus it was not possible to determine the effects of ITN due to the confounding effect of flooding, although decreases in An. darlingi density after inundation of larval habitats by higher than average rainfall and river levels have been documented previously in French Guiana and Brazil [95-97].

In 2007, under the programme PAMAFRO, the Organismo Andino de Salud (OAS, Andean Health Organization) began distributing LLINs throughout Colombia, Ecuador, Peru and Venezuela to reduce/eliminate regional Plasmodium transmission in concert with the push for global malaria eradication [98]. By 2010, when the campaign ended, OAS reported the distribution of approximately 346,000 LLINs protecting over 650,000 people. Between July and September 2007, 26,000 LLINs were provided to 194 targeted villages in Loreto, covering over 45,000 people. In a December survey of 60 villages, nearly $100 \%$ of households owned an LLIN, with $99 \%$ of children and $96 \%$ of pregnant women reporting use the previous night [99]. A follow-up survey in July 2008 found that ownership had dropped only slightly (to $98.7 \%$ ) but usage by children and pregnant women had decreased to 77.7 and $66.3 \%$, respectively [99].

El Niño Southern Oscillation (ENSO) events from 2006-2014 have been primarily attributed to La Niña, which produces dry conditions with reduced precipitation in Peru, though there was a moderate-level El Niño event from July 2009-April 2010 [100], that resulted in peak river levels greater than $10 \mathrm{~m}$ in April 2011, and high monthly average river levels from August 2010April 2011, compared to previous years [101]. Though it cannot be appropriately tested given the study design, possibly the PAMAFRO distribution of LLINs, together with the increased river levels at the end of the normally dry season in 2010 when An. darlingi numbers are typically low, contributed to the replacement event we identified. Disconcertingly, the number of malaria cases in Loreto has dramatically increased every year since 2011, despite decreases in the rest of Peru [36]. In 2010, there were 11,504 cases in Loreto ( $39.01 \%$ of cases in Peru) and 60,186 cases (93.7 \% of cases) in 2014 (see Additional file 7). The timing of this increase occurs just after both the LLIN distribution efforts and the 2009-2010 El Niño event, concomitantly with the population replacement event. The impact of this replacement event on the epidemiologies of $P$. vivax and $P$. falciparum appears to be minimal. Since 2008, the percentage of cases in Loreto due to $P$. vivax has hovered around 80 \% (range 78.9$84.7 \%$, with the minimum and maximum occurring in 2011 and 2009, respectively) [36].

Within the current peri-Iquitos An. darlingi population, Bayesian analyses detected subpopulations with differential distribution between highway and riverine habitats, but not among forest cover levels, suggesting local adaptation to human altered habitat. Though population B is significantly overrepresented in highway settings, further study, such as larval site surveys, is needed to confirm this potential adaptation. Previous studies in the Peruvian Amazon have linked An. darlingi presence and malaria transmission with the density and size of fish ponds $[55,102]$. Survey of these ponds for an overrepresentation of population $B$ larvae would provide evidence for the adaptation hypothesis. Recently, in western Amazonian Brazil, two subpopulations of An. darlingi were detected using microsatellites, whose distributions were associated with seasonal differences: "typical" $A n$. darlingi most abundant in the late rainfall period, and an anthropogenically-adapted group most abundant in the early rainfall period [56]. This second group is thought to use permanent, human-made larval sites since it is able to reach greater population size in the early rainfall season, before natural larval habitats are created, and persists in lower numbers than the first group throughout the remainder of the rainy season [56].

Vittor et al. [25, 55] conducted studies on the effect of forest cover and deforestation on biting rates and distribution of $A n$. darlingi in peri-Iquitos. These studies detected a significant association between highly deforested sites within villages and increased HBR in $A n$. darlingi, and were restricted to collection sites within highway habitat, to prevent confounding effects of riverine ecology on An. darlingi biting frequency. Within these sites, An. darlingi was consistently collected using human landing catch unimodally before midnight. The results in highway habitat collections of the current study were very similar, i.e., a significant effect of forest cover 
level on HBR, and unimodal biting before midnight. The 6-h HBRs (1800-24:00 h) calculated using the current study data (5.91, 1.79 and 0.63 in peridomestic, chacra and forest collections, respectively) were comparable to those of Vittor et al. [25] at equivalent forest cover levels 6.5 (4.9-8.0), $1.7(1.0-2.4)$ and $0.0(0.0-0.1)$ with increasing forest cover percentage.

However, the HBR was also significantly affected by habitat and the interaction between habitat and forest cover level. HBRs in riverine localities at the three forest cover levels were higher than their counterparts in highway localities, with the highest in peridomestic riverine collections. Additionally, An. darlingi biting in riverine collections was bimodal and statistically different from that of An. darlingi in highway. Peridomestic collection localities CAH and NPR (both riverine) had the highest HBRs, though they differed greatly in calculated forest cover percentage (Additional file 6). This result suggests that variation in HBR cannot be explained by forest cover percentage, but is likely a function of mosquito density (increased larval habitat in riverine habitat vs. highway), and increased biomass, including humans and domesticated animals [103]. To test this, distance from the peridomestic collection site (to the chacra and forest sites) was used as a proxy measure of biomass (increasing distance with decreasing biomass). After accounting for calculated forest cover and habitat, HBR was statistically significantly associated with distance, where HBR decreased with increasing distance from the peridomestic site $(p=0.000342,0.000651$ and 0.000185 , for HP, SI50 and SI100, respectively). Similar to the findings of Navia-Gine et al. [103], An. darlingi biting is proportional to the available host biomass in a given area.

Differences were also detected among forest cover levels with respect to biting pattern. Overall, peridomestic and chacra collections exhibited bimodal biting before and after midnight, with unimodal biting after midnight in forest collections. These patterns may be a function of the proximity of the collection sites to human populations and/or breeding sites [104, 105], a function of host choice [105], and/or a function of host availability [106]. Of the three forest cover level biting patterns, the only pattern with peaks at both dawn and dusk is that of the forest (Fig. 5b). This suggests that An. darlingi that were more zoophilic were collected from forest habitat which, according to Charlwood's hypothesis [105], would exhibit crepuscular biting, as opposed to more anthropophilic An. darlingi, which would bite nocturnally.

Overall, a Plasmodium infection rate (IR) of $0.63 \%$ was detected among An. darlingi collected during the peak malaria transmission period (April-June) in 2013 (Table 3). Despite the 2.5-fold higher IR in highway versus riverine collections ( 1.31 and $0.51 \%$, respectively), people living in riverine communities are at a threefold greater risk of Plasmodium infection due to the much greater HBR in this habitat. This pattern of risk was also detected in peridomestic versus chacra collections (IR: 0.51 and $2.07 \%$, and EIR: 0.23 and 0.10, respectively), and in the interaction between habitat and forest cover level (threefold greater risk in riverine vs. highway peridomestic collection sites, and fivefold greater risk in riverine vs. highway chacra collection sites). In this study, no Plasmodium transmission attributed to An. darlingi was detected in the forest, since An. darlingi are rarely captured in forest collections, even those only $300 \mathrm{~m}$ from a peridomestic collection site $[25,31,107,108]$. The overall Plasmodium, P. vivax and P. falciparum IRs (0.63, 0.44 and $0.15 \%$ ) determined in this study are similar to those published for An. darlingi collected in the periIquitos region in 2008 and 2009 [34]. Whereas the $A n$. darlingi IRs differed by season of collection in the Parker et al. [34], the IRs of the current study agree with those from specimens in [34] collected at the same time of year (April 2008; IRs $=0.89,0.74$, and $0.15 \%$, for Plasmodium, $P$. vivax, and $P$. falciparum, respectively). The IRs in the current study concur with previously reported rates in Brazil [109, 110]. Assuming PAMAFRO LLIN distribution and the 2010 ENSO event played a role in the population replacement event, the comparison of IRs between those reported by Parker et al. [34] and the current study demonstrate that the replacement event did not affect An. darlingi vector competence in the peri-Iquitos area.

Among the deforestation study samples that were genotyped using microsatellites ( $\mathrm{n}=156$ and 173 for subpopulation $A$ and $B$, respectively), eight were found to be infected with Plasmodium. Overall, subpopulation B had a higher Plasmodium IR (2.31 vs. $1.28 \%$ ) compared with A. Plasmodium-specific IRs in subpopulation B were also nearly double those of subpopulation A for both Plasmodium species $(1.16 \%$ for both $P$. vivax and $P$. falciparum in B versus $0.64 \%$ for both $P$. vivax and $P$. falciparum in A). This finding has implications for malaria epidemiology in the peri-Iquitos region, especially if the hypothesis of subpopulation B adaptation to human-altered environments is correct, allowing it to transmit year round.

A significant effect of forest cover level on wing length in An. darlingi suggests that larval habitats differ in quality among the three forest cover levels, since wing length is highly correlated to adult body size. Mosquito larvae living in nutrient-rich habitats become larger adult mosquitoes, whereas nutrient-poor habitats produce smaller adults [111]. A similar effect occurs as a result of increased competition in larval habitats in An. gambiae [112, 113]. An additional, non-mutually exclusive, 
explanation is changes in microclimatic conditions due to local deforestation [114]. In Kenya, deforested sites have been shown to experience higher midday temperatures than forested sites $[115,116]$. In An. gambiae, adult body size was negatively correlated with larval rearing temperature [117]. Additionally, temperature has been shown to have differing effects on mosquito development at different life stages and ultimately influences mosquito population dynamics and adult population age structure, with implications for vectorial capacity [118]. Body size has been shown to be positively correlated with vectorial capacity among mosquito vectors, due to the availability of fat stores and the energy needed to maintain Plasmodium infection [111], whereas temperature has a more complex relationship with Plasmodium, with peak transmission occurring at $25^{\circ} \mathrm{C}$ [119]. Decreased larval nutrition in An. darlingi is associated with increased biting frequency because these undernourished mosquitoes required more than one blood meal to complete a gonotrophic cycle [120], though the opposite result was seen in a separate study [121]. The decreased average wing length, and therefore body size, and presumed increased local temperature in peridomestic sites, may explain the decreased Plasmodium IR among these mosquitoes, compared to those from the chacra sites (overall 0.51 and $2.07 \%$, respectively; Table 3 ). However, the increased number of An. darlingi collected in peridomestic sites overcomes this difference, ultimately resulting in a twofold increased risk of malaria compared to chacra (Table 3).

\section{Conclusions}

Taken together, these results show that An. darlingi in Loreto, Peru underwent a drastic population replacement event after 2006 [46], consistent with the temporal population replacement hypothesis, though the role of the PAMAFRO LLIN distributions is confounded by a concurrent El Niño event. Population replacement of vectors is of great interest because new populations may be less susceptible to interventions currently in use, and/or may have altered behaviours and vectorial capacity. Substructuring within the new population collected between 2012 and 2014 was detected. These subpopulations differ in their distributions among highway and riverine habitats and Plasmodium IR, but not wing length, and may be in the early stages of adaptive divergence, providing evidence of ecological adaptation to human altered environments. Whereas HBR and biting pattern do not differ by subpopulation, these important vector biology metrics were associated with habitat and forest cover level, consistent with habitat differentiation. The results of this study show the need for a focus on vector control intervention in riverine settlements, which are hot spots of malaria transmission and risk in this region.

\section{Additional files}

Additional file 1. Anopheles darlingi collection information.

Additional file 2. Exemplar images depicting forest cover determination using satellite imagery. For each of the three forest cover levels, forest cover was calculated at both $50 \mathrm{~m}$ (inner circle) and $100 \mathrm{~m}$ (outer circle) radii from the collection site. Non-forest areas of the image were selected and colored pure black. The percentage of non-black pixels was determined using GIMP v.2.8.10 image software [64].

Additional file 3. Exemplar images depicting forest cover determination using hemispherical photography. For peridomestic and chacra forest cover levels, 30 randomly selected sites within $100 \mathrm{~m}$ of the collection site were chosen. At each site, a hemispherical image was taken directly upward to quantify the canopy coverage. Only one image was taken at the forest site, due to safety concerns. Canopy coverage in each image was determined using CAN-EYE v.6.314 [67] hemispherical image analysis software. In the lower images, a building was masked in the lower left corner, to prevent its classification as forest cover.

Additional file 4. Anopheles darlingi-specific microsatellite loci employed in this study and the length of the $72^{\circ} \mathrm{C}$ extension step at the end of the PCR program for each.

Additional file 5. Reanalysis of Anopheles darlingi collected in the peri-lquitos region in 2006, using microsatellites. (A) Anopheles darlingi collection sites from 2006 (white squares) and 2012-2014 (grey circles) near lquitos, Loreto, Peru (yellow star). (B) Population structure of Anopheles darlingi collected in the peri-lquitos region in 2006, reanalyzed using thirteen microsatellite loci. Collection of these specimens was previously described by Mirabelloet al. [46]. Optimal K=2. MAZ = Mazan; $\mathrm{NAU}=$ Nauta; $\mathrm{PCO}=$ Padre Cocha; ZUN = Zungarococha; PRT = Piura, Rio Tigre; SHP = Shishita, Pevas; SAE = San Esteban.

Additional file 6. Forest cover percentage determined using satellite imagery and hemispherical photography by locality and forest cover level.

Additional file 7. Number of malaria cases (Plasmodium vivax and Plasmodium falciparum) in all of Peru (solid line, triangle markers) versus Loreto department (dashed line, square markers) [36]. Timing of PAMAFRO long lasting insecticidal net distribution (LLIN; red solid line) and El Niño event (blue solid line) shown $[98,100]$.

\section{Authors' contributions}

WL, MM, PER, JMV and JEC designed the study; WL, MM, MPS and VMC contributed to field work; WL and SAB did molecular genotyping and Plasmodium testing; KN and MM contributed to molecular genotyping; MPS measured An. darlingi wing lengths; WL analysed data; WL wrote the first draft of the manuscript; JEC contributed significantly to revisions. All authors read and approved the final manuscript.

\section{Author details}

${ }^{1}$ Department of Biomedical Sciences, School of Public Health, State University of New York at Albany, Albany, NY, USA. ${ }^{2}$ Wadsworth Center, New York State Department of Health, Griffin Laboratory, 5669 State Farm Road, Building 1, Room 101, Slingerlands, NY 12159, USA. ${ }^{3}$ Division of Infectious Diseases, Department of Medicine, University of California, San Diego, La Jolla, CA, USA. ${ }^{4}$ Asociación Benéfica PRISMA, Iquitos, Peru. ${ }^{5}$ Universidade Estadual Paulista, São Paulo, Brazil. ${ }^{6}$ Instituto de Medicine Tropical "Alexander von Humboldt", Universidad Peruana Cayetano Heredia, Lima, Peru.

\section{Acknowledgements}

We are grateful to Melissa Leisner at the Applied Genomic Technologies Core at the Wadsworth Center, New York State Department of Health for genotyping microsatellite PCR products. We thank Kevin Riordan (Nazareth College, Rochester, NY) for ground truthing and image analysis advice. We are grateful 
to Lina Gutiérrez and Aline Angêlla for generously providing raw microsatellite data from their studies, Carl Schlichting for statistical advice, and Kevin Emerson for analytical advice and guidance. We thank all the people in the communities where the Anopheles darlingi were collected, and the hard working field team (Eliseo Ramirez, Jose Manuel Reyna, Victor Pacaya, David Arimuya, Hercules Maytahuari, Roland Rengifo, Asterio Rodriguez, Pablo Pacaya, Edward Vela, Romulo Rodriguez and Javier Rodriguez). Finally, we are grateful to Catharine Prussing and Katie D'Amico for their help with PCR amplification of some microsatellite loci. This work was supported by the International Centers for Excellence in Malaria Research grant U19AI089681 to JMV and by NIH Grant Al1 10112 to JEC. The Biodefense and Emerging Infectious Disease training fellowship Grant T32AI05532901 provided partial support for WL and VMC.

\section{Compliance with ethical guidelines}

\section{Competing interests}

The authors declare that they have no competing interests.

Received: 13 May 2015 Accepted: 23 August 2015

Published online: 29 September 2015

\section{References}

1. Helsinki ME, Hassan MM, El-Motasim WM, Malcolm CA, Knols BG, ElSayed B. Towards a sterile insect technique field release of Anopheles arabiensis mosquitoes in Sudan: irradiation, transportation, and field cage experimentation. Malar J. 2008;7:65.

2. Hay BA, Chen C-H, Ward CM, Huang H, Su JT, Guo M. Engineering the genomes of wild insect populations: challenges, and opportunities provided by synthetic Medea selfish genetic elements. J Insect Physiol. 2010;56:1402-13.

3. Gould F, Schiekelman P. Population genetics of autocidal control and strain replacement. Annu Rev Entomol. 2004;49:193-217.

4. Alphey L. Genetic control of mosquitoes. Annu Rev Entomol. 2013;59:204-24.

5. Gentile JE, Rund SSC, Madey GR. Modelling sterile insect technique to control the population of Anopheles gambiae. Malar J. 2015;14:92.

6. Klein TA, Windbichler N, Deredec A, Burt A, Benedict MQ. Infertility resulting from transgenic I-Ppol male Anopheles gambiae in large cage trials. Pathog Glob Health. 2012;106:20-31.

7. Yamada H, Vreysen MJB, Bourtzis K, TschirkW, Chadee DD, Gilles JRL. The Anopheles arabiensis genetic sexing strain ANO IPCL1 and its application potential for the sterile insect technique in integrated vector management programmes. Acta Trop. 2015;142:138-44.

8. Nolan T, Papathanos P, Windbichler N, Magnusson K, Benton J, Catteruccia F, et al. Developing transgenic Anopheles mosquitoes for the sterile insect technique. Genetica. 2011;139:33-9.

9. McArthur CC, Meredith JM, Eggleston P. Transgenic Anopheles gambiae expressing an antimalarial peptide suffer no significant fitness cost. PLoS One. 2014;9:e88625.

10. Dinsdale A, Schellhorn NA, De Barro P, Buckley YM, Riginos C. Rapid genetic turnover in populations of the insect pest Bemisia tabaci Middle East: Asia Minor 1 in an agricultural landscape. Bull Entomol Res. 2012;102:539-49.

11. Rochlin I, Gaugler R, Williges E, Farajollahi A. The rise of the invasives and decline of the natives: insights revealed from adult populations of container-inhabiting Aedes mosquitoes (Diptera: Culicidae) in temperate North America. Biol Invasions. 2012:15:991-1003.

12. Medlock JM, Hansford KM, Schaffner F, Versteirt V, Hendrickx G, Zeller H, et al. A review of the invasive mosquitoes in Europe: ecology, public health risks, and control options. Vector Borne Zoonotic Dis. 2012;12:435-47.

13. Paupy C, Delatte H, Bagny L, Corbel V, Fontenille D. Aedes albopictus, an arbovirus vector: from the darkness to the light. Microbes Infect. 2009;11:1177-85.

14. Kaufman MG, Fonseca DM. Invasion biology of Aedes japonicus japonicus (Diptera: Culicidae). Annu Rev Entomol. 2014;59:31-49.

15. Schaffner F, Vazeille M, Kaufmann C, Failloux A-B, Mathis A. Vector competence of Aedes japonicus for chikungunya and dengue viruses. Eur Mosq Bull. 2011;29:141-2.
16. Vega-Rúa A, Zouache K, Girod R, Failloux A-B, Lourenço-de-Oliveira R. High level of vector competence for Aedes aegypti and Aedes albopictus from ten American countries as a crucial Factor in the spread of Chikungunya virus. J Virol. 2014;88:6294-306.

17. Martins-Campos KM, Pinheiro WD, Vitor-Silva S, Siqueira AM, Melo GC, Rodrigues IC, et al. Integrated vector management targeting Anopheles darlingi populations decreases malaria incidence in an unstable transmission area, in the rural Brazilian Amazon. Malar J. 2012;11:351.

18. Shannon R. Anophelines of the Amazon Valley. Proc Entomol Soc Wash. 1933;35:117-43.

19. Calderón G, Fernández R, Valle J. Especies de la fauna anofelina, su distribucion y algunas consideraciones sobre su abundancia e infectividad en el Peru. Rev Peru Epidemiol. 1995:8:5-23.

20. Griffing SM, Gamboa D, Udhayakumar V. The history of the 20th century malaria control in Peru. Malar J. 2013;12:303.

21. Aramburu Guarda J, Ramal Asayag C, Witzig R. Malaria reemergence in the Peruvian Amazon region. Emerg Infect Dis. 1999;5:209-15.

22. Acosta J, Llancari M. Trabajos entomológicos en focos activos residuales de malaria. II-Estudios en el Río Yavarí. Servicios Nacionales de Erradicacion de Malaria-Ministerio de Salud de Peru; 1968.

23. Morales Ayala F. A list of the mosquitoes of Peru (Diptera, Culicidae) Mosq Syst Newsl. 1971;3:138-45.

24. Fernández R, Vera H, Calderón $G$. Historical review of the distribution of Anopheles (Nyssorhynchus) darlingi (Diptera: Culicidae) in the Peruvian Amazon. Rev Peru Med Exp Salud Pública. 2014;31:310-8.

25. Vittor AY, Gilman RH, Tielsch J, Glass G, Shields T, Sanches Lozano W, et al. The effect of deforestation on the human-biting rate of Anopheles darlingi, the primary vector of falciparum malaria in the Peruvian Amazon. Am J Trop Med Hyg. 2006;74:3-11.

26. Alhalel B. Infecciones emergentes y reemergentes en el Peru. In: Anales de la academia de medicina. Lima: Academia Nacional de Medicina; 2002.

27. Rogers E, Sholdt LL, Falcón R. Effects of incorporating chemical light sources in CDC traps: differences in the capture rates of Neotropical Culex, Anopheles and Uranotaenia (Diptera: Culicidae). Pan Pac Entomol. 1993;69:141-8.

28. Need JT, Rogers EJ, Phillips IA, Falcon R, Fernandez R, Carbajal F, et al. Mosquitoes (Diptera: Culicidae) captured in the lquitos area of Peru. J Med Entomol. 1993;30:634-8.

29. Fernández R, Carbajal F, Quintana J, Chauca H, Watts DM. Presencia del A. (N) darlingi (Diptera: Culicidae), en alrededores de la ciudad de lquitos, Loreto-Peru. Boletín de la Soc Peruana de Enfermedades Infecciosas y Trop. 1996;5:10-20.

30. Schoeler GB, Flores-Mendoza C, Fernandez R, Davila JR, Zyzak M. Geographical distribution of Anopheles darlingi in the Amazon Basin region of Peru. J Am Mosq Control Assoc. 2003;19:286-96.

31. Turell MJ, Sardelis MR, Jones JW, Watts DM, Fernandez R, Carbajal F, et al. Seasonal distribution, biology, and human attraction patterns of mosquitoes (Diptera: Culicidae) in a rural village and adjacent forested site near lquitos, Peru. J Med Entomol. 2008;45:1165-72.

32. Roper MH, Torres RSC, Goicochea CGC, Andersen EM, Guarda JSA, Calampa $C$, et al. The epidemiology of malaria in an epidemic area of the Peruvian Amazon. Am J Trop Med Hyg. 2000;62:247-56.

33. Moreno M, Saavedra MP, Bickersmith SA, Lainhart W, Tong C, Alava F, et al. Implications for changes in Anopheles darlingi biting behaviour in three communities in the peri-lquitos region of Amazonian Peru. Malar J. 2015;14:290.

34. Parker BS, Paredes Olortegui M, Penataro Yori P, Escobedo K, Florin D, Rengifo Pinedo $S$, et al. Hyperendemic malaria transmission in areas of occupation-related travel in the Peruvian Amazon. Malar J. 2013;12:178.

35. Reinbold-Wasson DD, Sardelis MR, Jones JW, Watts DM, Fernandez R, Carbajal F, et al. Determinants of Anopheles seasonal distribution patterns across a forest to periurban gradient near lquitos, Peru. Am J Trop Med Hyg. 2012;86:459-63.

36. Casos de malaria por departamentos Peru. 2014. http://www.dge.gob. pe/portal/docs/vigilancia/sala/2014/SE52/malaria.pdf. Accessed 14 Apr 2015.

37. Caputo B, Nwakanma D, Caputo FP, Jawara M, Oriero EC, HamidAdiamoh M, et al. Prominent intraspecific genetic divergence within Anopheles gambiae sibling species triggered by habitat discontinuities across a riverine landscape. Mol Ecol. 2014:23:4574-89. 
38. Shafer ABA, Wolf JBW. Widespread evidence for incipient ecological speciation: a meta-analysis of isolation-by-ecology. Ecol Lett. 2013; 16:940-50

39. Forattini OP. Culicidologia médica: identificação, biologia, epidemiologia/ Medical culicidology: ID, biology, epidemiology. EDUSP; 2002.

40. Manguin S, Wilkerson RC, Conn JE, Rubio-Palis Y, Danoff-Burg JA, Roberts DR. Population structure of the primary malaria vector in South America, Anopheles darlingi, using isozyme, random amplified polymorphic DNA, internal transcribed spacer 2, and morphologic markers. Am J Trop Med Hyg. 1999;60:364-76.

41. Emerson KJ, Conn JE, Bergo ES, Randel MA, Sallum MAM. Brazilian Anopheles darlingi (Diptera: Culicidae) clusters by major biogeographical region. PLoS One. 2015;10:e0130773.

42. Ruiz-Lopez F, Wilkerson RC, Conn JE, McKeon SN, Levin DM, Quinones $\mathrm{ML}$, et al. DNA barcoding reveals both known and novel taxa in the Albitarsis Group (Anopheles: Nyssorhynchus) of Neotropical malaria vectors. Parasit Vectors. 2012;5:44.

43. Foley DH, Linton YM, Ruiz-Lopez JF, Conn JE, Sallum MA, Povoa MM, et al. Geographic distribution, evolution, and disease importance of species within the Neotropical Anopheles albitarsis Group (Diptera, Culicidae). J Vector Ecol. 2014;39:168-81.

44. Wilkerson RC, Parsons TJ, Klein TA, Gaffigan TV, Bergo E, Consolim J. Diagnosis by random amplified polymorphic DNA polymerase chain reaction of four cryptic species related to Anopheles (Nyssorhynchus) albitarsis (Diptera: Culicidae) from Paraguay, Argentina, and Brazil. J Med Entomol. 1995;32:697-704.

45. Conn JE, Wilkerson RC, Segura MN, de Souza RT, Schlichting CD, Wirtz RA, et al. Emergence of a new neotropical malaria vector facilitated by human migration and changes in land use. Am J Trop Med Hyg. 2002;66:18-22.

46. Mirabello L, Vineis JH, Yanoviak SP, Scarpassa VM, Povoa MM, Padilla N, et al. Microsatellite data suggest significant population structure and differentiation within the malaria vector Anopheles darlingi in Central and South America. BMC Ecol. 2008;8:3.

47. Moreno M, Marinotti O, Krzywinski J, Tadei WP, James AA, Achee $\mathrm{NL}$, et al. Complete mtDNA genomes of Anopheles darlingi and an approach to anopheline divergence time. Malar J. 2010;9:127.

48. Pedro PM, Sallum MAM. Spatial expansion and population structure of the neotropical malaria vector, Anopheles darlingi (Diptera: Culicidae). Biol J Linn Soc Lond. 2009:97:854-66.

49. Mirabello L, Conn JE. Molecular population genetics of the malaria vector Anopheles darlingi in Central and South America. Heredity (Edinb). 2006;96:311-21.

50. Pinedo-Cancino V, Sheen P, Tarazona-Santos E, Oswald WE, Jeri C, Vittor AY, et al. Limited diversity of Anopheles darlingi in the Peruvian Amazon region of lquitos. Am J Trop Med Hyg. 2006;75:238-45.

51. Rozendaal JA. Observations on the distribution of anophelines in Suriname with particular reference to the malaria vector Anopheles darlingi. Mem Inst Oswaldo Cruz. 1990;85:221-34.

52. Hudson J. Anopheles darlingi root (Diptera, Culicidae) in the Suriname rainforest. Bull Entomol Res. 1984;74:129-42.

53. Manguin S, Roberts DR, Andre RG, Rejmankova E, Hakre S. Characterization of Anopheles darlingi (Diptera: Culicidae) larval habitats in Belize,Central America. J Med Entomol. 1996;33:205-11.

54. Gil LH, Tada MS, Katsuragawa TH, Ribolla PE, da Silva LH. Urban and suburban malaria in Rondonia (Brazilian Western Amazon) II. Perennial transmissions with high anopheline densities are associated with human environmental changes. Mem Inst Oswaldo Cruz. 2007;102:271-6.

55. Vittor AY, Pan W, Gilman RH, Tielsch J, Glass G, Shields T, et al. Linking deforestation to malaria in the Amazon: characterization of the breeding habitat of the principal malaria vector, Anopheles darlingi. Am J Trop Med Hyg. 2009;81:5-12.

56. Angêlla AF, Salgueiro P, Gil LH, Vicente JL, Pinto J, Ribolla PE. Seasonal genetic partitioning in the neotropical malaria vector, Anopheles darlingi. Malar J. 2014;13:203.

57. Hiwat H, Mitro S, Samjhawan A, Sardjoe P, Soekhoe T, Takken W. Collapse of Anopheles darlingi populations in Suriname after introduction of insecticide-treated nets (ITNs); malaria down to near elimination level. Am J Trop Med Hyg. 2012;86:649-55.
58. Faran ME. Mosquito studies (Diptera, Culicidae) XXXIV. A revision of the Albimanus section of the subgenus Nyssorhynchus of Anopheles. Contributions of the American Entomological Institute. 1980;15:1-215.

59. Faran ME, Linthicum KJ. A handbook of the Amazonian species of Anopheles (Nyssorhynchus) (Diptera: Culicidae). Mosq Syst. 1981;13:1-81.

60. Consoli RA, Lourenco-de-Oliveira R. Principais mosquitos de importância sanitária no Brasil. Fundação Oswaldo Cruz: Editora Fiocruz; 1994.

61. Censo. 2007. http://censos.inei.gob.pe/cpv2007/tabulados/. Accessed 27 Feb 2015.

62. Bioclim. www.worldclim.org/bioclim. Accessed 16 Jan 2015.

63. Hiwat H, Bretas G. Ecology of Anopheles darlingi Root with respect to vector importance: a review. Parasit Vectors. 2011;4:177.

64. GNU Image Manipulation Program. 2014. www.gimp.org. Accessed 20 Mar 2014.

65. Rich PM. Characterizing plant canopies with hemispherical photographs. Remote Sens Rev. 1990;5:13-29.

66. Chianucci F, Cutini A. Estimation of canopy properties in deciduous forests with digital hemispherical and covery photography. Agric For Meteorol. 2013;168:130-9.

67. CAN-EYE. 2014. http://www6.paca.inra.fr/can-eye. Accessed 16 Apr 2014.

68. Conn JE, Bollback JP, Onyabe DY, Robinson TN, Wilkerson RC, Póvoa MM Isolation of polymorphic microsatellite markers from the malaria vector Anopheles darlingi. Mol Ecol Notes. 2001;1:223-5.

69. Lima GN, Batista JS, Formiga KM, Cidade FW, Rafael MS, Tadei WP, et al. New 24 polymorphic DNA microsatellite loci for the major malaria vector Anopheles darlingi and trans species amplification with another anophelines. Conserv Genet Resour. 2010;2:205-9.

70. Glaubitz JC. CONVERT: a user-friendly program to reformat diploid genotypic data for commonly used population genetic software packages. Mol Ecol Notes. 2004:4:309-10.

71. Conn JE, Vineis JH, Bollback JP, Onyabe DY, Wilkerson RC, Povoa MM. Population structure of the malaria vector Anopheles darlingi in a malaria-endemic region of eastern Amazonian Brazil. Am J Trop Med Hyg. 2006;74:798-806

72. Scarpassa VM, Conn JE. Population genetic structure of the major malaria vector Anopheles darlingi (Diptera: Culicidae) from the Brazilian Amazon, using microsatellite markers. Mem Inst Oswaldo Cruz. 2007;102:319-27.

73. Gutiérrez LA, Gomez GF, Gonzalez JJ, Castro MI, Luckhart S, Conn JE, et al. Microgeographic genetic variation of the malaria vector Anopheles darlingi root (Diptera: Culicidae) from Cordoba and Antioquia, Colombia. Am J Trop Med Hyg. 2010;83:38-47.

74. Pritchard JK, Stephens M, Donnelly P. Inference of population structure using multilocus genotype data. Genetics. 2000;155:945-59.

75. Falush D, Stephens M, Pritchard JK. Inference of population structure using multilocus genotype data: linked loci and correlated allele frequencies. Genetics. 2003;164:1567-87.

76. Earl DA, vonHoldt BM. STRUCTURE HARVESTER: a website and program for visualizing STRUCTURE output and implementing the Evanno method. Conserv Genet Resour. 2012;4:359-61.

77. Jakobsson M, Rosenberg NA. CLUMPP: a cluster matching and permutation program for dealing with label switching and multimodality in analysis of population structure. Bioinformatics. 2007;23:1801-6.

78. Cavalli-Sforza LL, Edwards AW. Phylogenetic analysis. Models and estimation procedures. Am J Hum Genet. 1967;19:233-57.

79. Langella O. Populations. 1.2.30 edition. CNRS UPR90341999. 2014. http://bioinformatics.org/populations/. Accessed 14 Dec 2014

80. Mesquite: a modular system for evolutionary analysis. Version 2.75 2014. http://mesquiteproject.org. Accessed 14 Dec 2014.

81. Belkhir K, Borsa P, Chikhi L, Raufaste N, Bonhomme F. GENETIX 4.05, logiciel sous Windows(TM) pour la génétique des populations. Montpellier: Laboratoire Génome, Populations, Interactions, CNRS UMR 5171, Université de Montpellier; 1996-2004.

82. Vaha JP, Primmer CR. Efficiency of model-based Bayesian methods for detecting hybrid individuals under different hybridization scenarios and with different numbers of loci. Mol Ecol. 2006;15:63-72.

83. Excoffier $\mathrm{L}$, Lischer HEL. Arlequin suite ver 3.5: a new series of programs to perform population genetics analyses under Linux and Windows. Mol Ecol Resour. 2010;10:564-7. 
84. Wright S. Variability within and among natural populations. In: Evolution and the genetics of populations, vol 4. Chicago, IL: The University of Chicago Press; 1978.

85. Beaumont MA, Nichols RA. Evaluating loci for use in the genetic analysis of population structure. Proc R Soc Lond B. 1996;263:1619-26.

86. Antao T, Lopes A, Lopes RJ, Beja-Pereira A, Luikart G. LOSITAN: a workbench to detect molecular adaptation based on a Fst-outlier method. BMC Bioinform. 2008;9:323.

87. Slatkin M. Gene flow and the geographic structure of natural populations. Science. 1987;236:787-92.

88. The R Project for Statistical Computing. 2014. www.r-project. org. Accessed 3 Dec 2014.

89. Bickersmith SA, Lainhart W, Moreno M, Chu VM, Vinetz JM, Conn JE. A sensitive, specific and reproducible real-time PCR method for detection of Plasmodium vivax and P. falciparum infection in field-collected anophelines. Mem Inst Oswaldo Cruz. 2015;110:573-6.

90. Pritchard JK, Wen X, Falush D. Documentation for structure software: version 2.3. 2010.

91. Estoup A, Rousset F, Michalakis Y, Cornuet JM, Adriamanga M, Guyomard R. Comparative analysis of microsatellite and allozyme markers: a case study investigating microgeographic differentiation in brown trout (Salmo trutta). Mol Ecol. 1998;7:339-53.

92. Kothera L, Godsey MS Jr, Doyle MS, Savage HM. Characterization of Culex pipiens complex (Diptera: Culicidae) populations in Colorado, USA using microsatellites. PLoS One. 2012;7:e47602.

93. Krayter L, Alam MZ, Rhajaoui M, Schnur LF, Schonian G. Multilocus microsatellite typing reveals intra-focal genetic diversity among strains of Leishmania tropica in Chichaoua Province, Morocco. Infect Genet Evol. 2014;28:233-9.

94. Hartl DL, Clark AG. Principles of population genetics. 4th ed. Sunderland: Sinauer Associates; 2007.

95. Pajot F-X, Le Pont F, Molez J-F, Degallier N. Aggressivité d'Anopheles (Nyssorhynchus) darlingi Root, 1926 (Diptera, Culicidae) en Guyane française. Cahiers ORSTOM Entomologie Médicale et Parasitologie. 1977;15:15-22.

96. Charlwood J. Observations on the bionomics of Anopheles darlingi Root (Diptera; Culicidae) from Brazil. Bull Entomol Res. 1980;70:685-92.

97. Forattini OP. Exophilic behaviour of Anopheles darling Root in a southern region of Brazil. Rev Saude Publica. 1987;21:291-304.

98. OAS. Estrategia basada en la implementación de mosquiteros tratados con insecticidas (MTI) - Aporte del Proyecto PAMAFRO. Lima, Peru: Organismo Andino de Salud - Convenio Hipólito Unanue; 2011.

99. Rosas-Aguirre A, Guzman-Guzman M, Moreno-Gutierrez D, RodriguezFerrucci H, Vargas-Pacherrez D, Acuna-Gonzalez Y. Long-lasting insecticide - treated bednet ownership, retention and usage one year after their distribution in Loreto, Peru. Rev Peru Med Exp Salud Publica. 2011;28:228-36

100. Cold and Warm Episodes by Season. 2015. http://www.cpc.ncep. noaa.gov/products/analysis_monitoring/ensostuff/ensoyears. shtml. Accessed 18 Mar 2015.

101. Hydrological Station\# 47252718 in Punchana, Maynas, Loreto, Peru. 2015. http://www.senamhi.gob.pe/main_mapa.php. Accessed 18 Mar 2015.

102. Maheu-Giroux M, Casapía M, Soto-Calle VE, Ford LB, Buckeridge DL, Coomes OT, et al. Risk of malaria transmission from fish ponds in the Peruvian Amazon. Acta Trop. 2010;115:112-8.

103. Navia-Gine WG, Loaiza JR, Miller MJ. Mosquito-host interactions during and after an outbreak of equine viral encephalitis in eastern Panama. PLoS One. 2013;8:e81788.

104. Zimmerman RH, Lounibos LP, Nishimura N, Galardo AK, Galardo CD, Arruda ME. Nightly biting cycles of malaria vectors in a heterogeneous transmission area of eastern Amazonian Brazil. Malar J. 2013;12:262.

105. Charlwood JD. Biological variation in Anopheles darlingi Root. Mem Inst Oswaldo Cruz. 1996:91:391-8.

106. Zimmerman RH, Galardo AK, Lounibos LP, Arruda M, Wirtz R. Bloodmeal hosts of Anopheles species (Diptera: Culicidae) in a malaria-endemic area of the Brazilian Amazon. J Med Entomol. 2006;43:947-56.
107. Hiwat H, Issaly J, Gaborit P, Somai A, Samjhawan A, Sardjoe P, et al. Behavioral heterogeneity of Anopheles darlingi (Diptera: Culicidae) and malaria transmission dynamics along the Maroni River, Suriname, French Guiana. Trans R Soc Trop Med Hyg. 2010;104:207-13.

108. Dusfour I, Carinci R, Issaly J, Gaborit P, Girod R. A survey of adult anophelines in French Guiana: enhanced descriptions of species distribution and biting responses. J Vector Ecol. 2013;38:203-9.

109. Tadei WP, Dutary Thatcher B. Malaria vectors in the Brazilian amazon: Anopheles of the subgenus Nyssorhynchus. Rev Inst Med Trop Sao Paulo. 2000;42:87-94.

110. de Oliveira-Ferreira J, Lourenco-de-Oliveira R, Teva A, Deane LM, DanielRibeiro CT. Natural malaria infections in anophelines in Rondonia State, Brazilian Amazon. Am J Trop Med Hyg. 1990;43:6-10.

111. Moller-Jacobs LL, Murdock CC, Thomas MB. Capacity of mosquitoes to transmit malaria depends on larval environment. Parasit Vectors. 2014;7:593.

112. Gimnig JE, Ombok M, Otieno S, Kaufman MG, Vulule JM, Walker ED. Density-dependent development of Anopheles gambiae (Diptera: Culicidae) larvae in artificial habitats. J Med Entomol. 2002;39:162-72.

113. Russell TL, Lwetoijera DW, Knols BG, Takken W, Killeen GF, Ferguson HM. Linking individual phenotype to density-dependent population growth: the influence of body size on the population dynamics of malaria vectors. Proc Biol Sci. 2011;278:3142-51.

114. Patz JA, Olson SH. Malaria risk and temperature: influences from global climate change and local land use practices. Proc Natl Acad Sci USA. 2006;103:5635-6.

115. Afrane YA, Zhou G, Lawson BW, Githeko AK, Yan G. Effects of microclimatic changes caused by deforestation on the survivorship and reproductive fitness of Anopheles gambiae in western Kenya highlands. Am J Trop Med Hyg. 2006;74:772-8.

116. Afrane YA, Lawson BW, Githeko AK, Yan G. Effects of microclimatic changes due to land use and land cover on duration of gonotrophic cycles of Anopheles gambiae (Diptera: Culicidae) in western Kenya highlands. J Med Entomol. 2005;42:974-80.

117. Lyimo EO, Takken W, Koella JC. Effect of rearing temperature and larval density on larval survival, age at pupation and adult size of Anopheles gambiae. Entomol Exp App. 1992;63:265-71.

118. Beck-Johnson LM, Nelson WA, Paaijmans KP, Read AF, Thomas MB, Bjørnstad ON. The effect of temperature on Anopheles mosquito population dynamics and the potential for malaria transmission. PLoS One. 2013;8:e79276.

119. Mordecai EA, Paaijmans KP, Johnson LR, Balzer C, Ben-Horin T, de Moor $E$, et al. Optimal temperature for malaria transmission is dramatically lower than previously predicted. Ecol Lett. 2013;16:22-30.

120. de Oliveira CD, Tadei WP, Abdalla FC, Paolucci Pimenta PF, Marinotti O. Multiple blood meals in Anopheles darlingi (Diptera: Culicidae). J Vector Ecol. 2012;37:351-8

121. Araujo M, Gil LH, e-Silva A. Larval food quantity affects development time, survival and adult biological traits that influence the vectorial capacity of Anopheles darlingi under laboratory conditions. Malar J. 2012;11:261.

122. DIVA-GIS. 2015. www.diva-gis.org/gdata. Accessed 3 Jan 2015

\section{Submit your next manuscript to BioMed Central and take full advantage of:}

- Convenient online submission

- Thorough peer review

- No space constraints or color figure charges

- Immediate publication on acceptance

- Inclusion in PubMed, CAS, Scopus and Google Scholar

- Research which is freely available for redistribution

Submit your manuscript at

www.biomedcentral.com/submit 